$4-1-2014$

\title{
Understanding Knowledge Management Software-Organisation Misalignments From An Institutional Perspective: A Case Study Of A Global IT-Management Consultancy Firm
}

\author{
Khuong Le-Nguyen \\ Cleveland State University, k.lenguyen@csuohio.edu \\ G. Harindranath \\ University of London
}

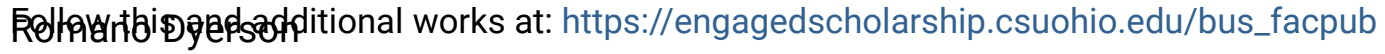

dikersityfoflendoness Commons

How does access to this work benefit you? Let us know!

\section{Publisher's Statement}

NOTICE: this is the author's version of a work that was accepted for publication in the

International Journal of Information Management. Changes resulting from the publishing process, such as peer review, editing, corrections, structural formatting, and other quality control mechanisms may not be reflected in this document. Changes may have been made to this work since it was submitted for publication. A definitive version was subsequently published in the International Journal of Information Management, 34, 2, 04-01-2014, 10.1016/

j.ijinfomgt.2013.11.003.

\section{Original Published Citation}

Le-Nguyen, K., Harindranath, G., \& Dyerson, R. (2014). Understanding knowledge management softwareorganisation misalignments from an institutional perspective: A case study of a global IT-management consultancy firm. International Journal of Information Management, 34(2), 226-247. doi: 10.1016/ j.jinfomgt.2013.11.003

This Article is brought to you for free and open access by the Monte Ahuja College of Business at EngagedScholarship@CSU. It has been accepted for inclusion in Business Faculty Publications by an authorized administrator of EngagedScholarship@CSU. For more information, please contact library.es@csuohio.edu. 


\title{
Understanding knowledge management software-organisation misalignments from an institutional perspective: A case study of a global IT-management consultancy firm
}

\author{
Khuong Le-Nguyen ${ }^{\mathrm{a}, *}, \mathrm{G}$. Harindranath ${ }^{\mathrm{b}}$, Romano Dyerson ${ }^{\mathrm{b}}$ \\ ${ }^{a}$ Cleveland State Univ, Monte Ahuja College of Business, Cleveland, OH 44115, United States \\ ${ }^{\mathrm{b}}$ School of Management, Royal Holloway College, University of London, Egham, Surrey, TW20 0EX, UK
}

\section{Introduction}

In recent years organisations worldwide have acquired and implemented knowledge management (KM) software, believing that such Commercial Off-The-Shelf packages can boost their innovation, creativity and responses to meet the ever-increasing market demands. An increasing number, however, have not gained the expected benefits from the technology and even worse, faced critical failures (Malhotra, 2005). For example in 2002, businesses spent US\$2.7 billion into new KM systems (Barrett \& Walsham, 1999). As reflected by McDermott, "The great trap in knowledge management is using information management tools and concepts to design knowledge management systems"(McDermott, 2000, p. 27). Understandably if KM technology is not properly aligned with organisational needs and with people's ways of working, or if it results in information overload, then even with the cutting-edge technology, organisations would end up right back at square one: they cannot have the knowledge they need.

In this study, the potential for misalignment can be explained as follows. Whilst KM software packages may be configured to meet a wide range of organisational requirements and even integrated with 'best practices', a poor record of implementation success (Malhotra, 2005) suggests that, in some instances, the misfit between the context of adoption environment and the context within which the software was developed may be significant. Put

\footnotetext{
* Corresponding author. Tel.: +1 2166873795.

E-mail address: khuong109@gmail.com (Le-Nguyen Khuong).
}

another way, the privileging of commodification here is problematic for the organisations. To tackle this misfit, organisations could opt for software customisation or organisational adaptation. However, these 'solutions' may themselves be problematic by increasing implementation risks, promoting inefficient workarounds and bear serious implications for future support and maintenance (Besson \& Rowe, 2001). In this regard, our reading of literature highlights a lack of research into the fundamental contextual differences between KM technology developer and the adopter. Here we explore the 'black-box' of KM software-organisation misalignment when the speed of software adoption gains greater momentum worldwide.

Using a case study of an IT-management consulting company ranked among the world's top 20 companies and whose offices are located throughout the world, this paper focuses on the causes and types of misalignments identified from a knowledge portal implementation. Specifically, this paper attempts to address this question: How do misalignments of KM software implementation impact on the adopter's strategic responses? Answering this question can help facilitate senior management to better control the KM project. To address this question, we draw upon institutional theory (DiMaggio \& Powell, 1983; Oliver, 1991; Scott, 1987, 1995) and the extended theory on the structurational properties of technology (Orlikowski, 1992, 2000) to develop a framework to analyse instances of misalignment. Orlikowski suggests that there is ' $a$ duality of structures': structures (as reflected by assumptions along with knowledge of the work being automated, resources to accomplish the work and rules that define the organisationally sanctioned way of executing that work) that are inherent to advanced 
technologies (and hence, anticipated by designers and sponsors) and the structures that emerge in human action as users interact with these technologies. Differences in terms of such structures are viewed from the perspective of institutional theory, which provides insights into how organisations, technology developers and adopters alike, deliberately acquire, or have imposed on them, certain structures to gain legitimacy in their environment and thus to help sustain their business in the long-term (Meyer \& Rowan, 1977).

Though there are some studies employing the notion of structures to understand how technologies are implemented in organisational life, a lot of aspects remain uncovered (Orlikowski \& Scott, 2008). For example, by using structures Majchrzak, Rice, Malhotra, King, and Ba (2000) explore the interaction between a virtual team and a collaborative technology, whilst Soh, Sia, Wai, and May (2003) Soh and Sia (2004) and Sia and Soh (2007) investigate the implementation of ERP systems in healthcare and defence industries. Most noteworthy, among numerous studies of KM technologies implementation in the literature, the fact that little is known of what and how institutional structures are embedded, appropriated and changed in KM technology implementation projects has also been an impetus for undertaking research on this issue.

The remainder of the paper is organised into four sections. Section 2 reviews the misalignments between the context of KM software and that of adopting organisations. Section 3 introduces research methodology and the research framework. Section 4 briefly introduces the case company and presents data analysis and findings. The last section discusses the issues related to findings and gives some conclusions and suggestions for future research.

\section{Literature review}

\subsection{Understanding the structures embedded in the software and organisations}

Typing in 'technology' in the Google search box conjures up a bewildering array of alternative definitions sometimes focusing on the physical reality of crafted equipment used in the production of goods and services, and at other times concentrating on the knowledge and skills inherent in the crafting of such equipment. A broad definition of technology would ideally acknowledge both the system of knowledge necessary for the manufacture of goods and services together with how technology mediates the environment around individuals and around organisations. In other words, 'technology' as such rarely arrives fully formed but requires mediation. Software for example typically requires appropriation and modification by end-users during operation because end-users are usually unaware of the developers' context and their embedded assumptions and rules (Orlikowski, 1992, 2000). Technology developers engrave their assumption or understanding of the surrounding world in the technology configuration (Latour, 1992; see also Gosain, 2004). Such an assumption or understanding of the world is influenced by the institutional properties of their particular work setting and draws on certain components of their institutional context such as knowledge, resources, and norms to design technology products (Orlikowski, 1992; see also Besson \& Rowe, 2001; Gosain, 2004; Sia \& Soh, 2007; Soh \& Sia, 2004; Soh et al., 2003). Notably, the spirit of technology, represented by appropriate behaviours in the context of technology, the understanding and interpreting of technology use, and making technology performance explicit and feasible, is affected by its developers' institutional context and then reflected in the goals and values underlying the structural features of the technology. These 'structural' features then incorporate institutional structures such as reporting hierarchies, organisational knowledge and standard operating procedures as rules, resources, and capabilities in the technology (DeSanctis \&
Poole, 1994). As such, it is understandable that the institutional contexts impinge upon the structures embedded in the technology or the implementing organisation. Consequently, most organisations face significant knowledge barriers in reflecting their context in their implementation (Robey, Ross, \& Boudreau, 2002).

Many of these things hold true of KM software, which enables KM processes. For example, KM software developers draw on their existing sources of knowledge, resources, and norms including their own corporate vision, business strategies, and prevailing rules and norms about what constitutes good practices (Gosain, 2004; Markus \& Tanis, 2000; Soh et al., 2003). In accordance with institutional theory, to design the software package technology, developers have to project the organisational requirements, and tend to learn from organisations in their home market with which they have relationships and other markets where they have official contacts or representation (Meyer, 1994; Nicolaou, 1999). Besides, the institutional perspective allows us to distinguish between country-level and industry-level differences. ${ }^{1}$ For example, KM software firms in the UK need to understand both the UK's laws and the industry's standards of maintaining personal privacy and identity as well as company information. They may seek a short cut to this process by seeking out the experiences of pioneers in the marketplace. Eventually the structures embedded in the Commercial Off-The-Shelf product would reflect the context of the association or cluster of organisations with which the developers frequently interacted during the system design and development.

Due to active agency, organisations may respond differently to the institutional contexts surrounding their enterprise systems (Currie \& Suhomlinova, 2006; Gosain, 2004). In the case of KM software packages, the developer's institutional context could be different from that of many other potential adopters. Such a difference may be exacerbated where adopters are from different countries, industries, and sectors than the original association or cluster of exemplary organisations. KM software implementation is now expanding beyond the Western European or North American markets where many well-known and competent KM software developers are located. Alternatively, some organisations operating in a legal sector may purchase KM software that is more suitable for those in a financial services sector. From an institutional perspective, if we consider the coercive force (i.e., governmental regulations and legislation), legal firms are affected by a set of institutional structures (e.g., rules of collecting and storing information, rules of producing reports for clients, etc.) that may be different from that of financial services institutions (i.e., rules for sharing and transferring data, norms of maintaining the integrity of customers' and company internal information). Interestingly, even organisations operating within the same industry in a country may not share the same vision and knowledge of KM systems and practices due to differences in a company's history and profile (Powell \& DiMaggio, 1991), differences in economic, social and cultural background (i.e., organisations locate nationwide), and differences in reacting to market forces (i.e., considering the five-force model of Porter (1996)) and, thus, as Farjoun (2002) suggests, possess different sets of institutional structures. Such a difference in the same organisational field is also due to the variations in the nature and strength of institutional forces exercised on different parts of an organisational field (Currie \& Suhomlinova, 2006). The two giants in semi-conductor manufacturing, Intel and AMD, are good illustrations since they are in the same country and industry but do not seem to completely share the same institutional structures.

Empirical evidence suggests that critical differences between the rules, resources, and norms embedded in KM technology and in

\footnotetext{
1 These issues will be further discussed in Section 2.2.
} 
the implementing environment can even result in negative consequences, such as the collapse of many KM technology programmes (Kontzer, 2003) including the inefficient and costly performance of British Aerospace's knowledge portal (Hoffman, 2002), or the Columbia space shuttle's knowledge sharing and integration system malfunction in 2003 (Computer Weekly, 2003). The reasons for such consequences may be attributed to the separation of developers from users in terms of time and space (Orlikowski, 1992) and that users tend to abandon any attempt to enhance the interpretive flexibility of technology (Pozzebon, 2001). Problems arise when these fundamental issues are not taken into account until later in the implementation phase. Though prior studies have employed different institutional arguments, there is a consensus on the mechanism of how organisations are imposed upon by and deliberately adopt institutional structures to gain legitimacy (Scott, 1987). The next sections will elaborate these mechanisms.

\subsection{Structures that are imposed on organisations}

According to institutional theory, organisations are imposed upon by two types of authorised sources: the coercive authority of nation-states, and the normative authority of professions and industry (DiMaggio \& Powell, 1983; Scott, 1987). By promulgating laws and regulations countries exert coercive pressures, and organisations accept the requisite structures to embed in their business processes to maintain legitimacy in their environment. For example, Massey, Montoya-Weiss, and O'Driscoll (2002) identify the case of Nortel Networks, which went through many changes in its KM initiative due to the government's deregulation of the telecommunications industry. Indeed, before deregulation, those operating in the telecom industry were governed by many of the state's rules affecting firms' innovation and competition. In particular, organisations operating in highly regulated domains tend to have information systems with similar mandated structures (Gosain, 2004).

Different countries exercise different types of institutional pressures and organisations will therefore need to adopt differing requisite structures (Gosain, 2004). Problems, however, could arise when the implementing organisation is based in a country whose institutional pressures are different from those existing in the home countries of the developers. Generally, there are many dimensions in which countries differ from each other; yet only certain differences will be relevant for analysing potential causes of misalignments with regard to KM software implementation. Since KM software is meant to support the processes of knowledge and creativity entities, differences in national knowledge and intellectual institutions should be considered. The knowledge and intellectual institutions and the laws and regulations imposed by each country on the organisations operating within its boundaries reflect its values and norms. In some countries, the government could play a decisive role in knowledge and intellectual property activity, and KM software designed and developed in or for such markets may inherently have features protecting intellectual property rights or nurturing innovation. For instance, KM software, if outsourced to a country where intellectual property and privacy are not strictly protected, may not be incorporated with the strong intellectual property protection required by certain developed countries (such as the UK, Switzerland and Singapore). Software adopters should therefore consider the extent to which national level laws and regulations pertaining to industry standards, knowledge, intellectual property, privacy with organisational identity and confidentiality (Malhotra, 2004), information security, human resource and cultural issues (Akhavan \& Jafari, 2006), trade between organisations and between organisations and other key players in the value chain (Dyer \& Nobeoka, 2000; Malhotra, 2004), and new product and service development are different from those assumed by software developers from their own context.

Besides, the coercive pressures created by nation-states, industry and professional associations, or networks are more likely to create normative pressures through guidelines on good practices and industry accreditation and recognition of organisations, or inter-relationship of firm-supplier and firm customer (Burt, 1982; Dyer \& Nobeoka, 2000; Massey et al., 2002; Scott, 1987). To gain a certain level of recognition of the industry, organisations have to follow procedures that are appropriate to their operation (Meyer \& Rowan, 1977). For instance, the AS 5037-2005 standard gives guidelines on designing KM for any community or organisation (SAIGlobal, 2007). Asian Knowledge Management Association (AKMA) in Hong Kong is the first professional body to have developed a series of certification standards specific to KM (i.e., KM 8001), intellectual property protection (IP 8001), and intellectual capital realisation (IC 8001) (Asian Knowledge Management Association, 2007).

As mentioned above, organisations operating in different industries or sectors may also possess different institutional structures. The contextual differences of industry impinge on the structures incorporated into KM technology, as well as the structures embedded in the implementing organisations, and empirical studies have shown how such differences have lead to organisational problems. For example, Malhotra (2004) identifies the case where integration of data and processes across inter-enterprise value networks imposes certain challenges of organisational control on the design of KM systems. In effect, if the organisation adopts a KM system, which shares accurate information related to goods or services flowing across the supply chain without considering the potentially paradoxical roles of collaboration and competition adopted by various players in the same supply chain, then the organisation is likely to face peril in its operation. Another interesting case is Toyota, which has established network rules/norms, including the imposition of economic sanctions (e.g., withdraw business), and including only those players in its supply chain who agree to openly share their knowledge resources (Dyer \& Nobeoka, 2000). Network members must therefore design their own KM systems in a way that facilitates 'open sharing'.

From a Knowledge-Based perspective (Spender, 1996; Grant, 1996), Kogut and Zander (1996) and DeCarolis and Deeds (1999) also provide the important insight that the speed, efficiency and accessibility $^{2}$ of the knowledge types could be in part identified through industry and professional differences. Differences in knowledge types will give rise to differences in routines and structures for extracting, distributing, applying, and re-using the knowledge (Maier \& Remus, 2001; Tiwana, 2000). KM software designed and developed in the context of industries with lower requirements for speed, efficiency, and accessibility may not have the competent routines and structures to support the KM processes for an industry where similar requirements are set very high. For instance, whilst a public council and a management consultancy firm have a similar need to provide staff and clients with knowledge about their services, the requirements for speed and accessibility of a knowledge portal in a consultancy firm could be higher than that of a public council. There are implications of what acceptable degrees of such dimensions are. Pushing and pulling knowledge items in the portal and search engine for a consultancy firm could likely require more complex and sophisticated features and procedures than those designed for a public service organisation.

\footnotetext{
2 Kogut and Zander (1996, p. 503) suggest organisations look for the "speed and efficiency" of the technological solution in enabling the knowledge process. Alternatively, the technology must also enable 'differential access to externally generated knowledge' (DeCarolis \& Deeds, 1999, p. 954).
} 


\subsection{Structures that are deliberately acquired by the organisations}

In addition to the imposed structures organisations also deliberately acquire certain structures. Institutional theory has identified two types of pressures affecting organisations: mimetic pressure arising from the uncertainty of the business environment, and the normative pressure arising from the inter-relationship between firms within a profession, business and trade (Burt, 1982; DiMaggio \& Powell, 1983; Scott, 1987). When the business environment is volatile, organisations experience the mimetic pressure by modelling their structures on other organisations in their fields (i.e., competitors and peers) that are perceived as more legitimate or successful. Alternatively, thanks to participating in a professional or trade body, good structures are promoted and shared among members for the sake of improving their performance (Scott, 1987).

More proactively, other mechanisms also explain why organisations voluntarily adopt structures. New institutional theory embraces a variety of strategic responses to the institutional environment (Oliver, 1991), acknowledging that an organisation's self-interests and active agency facilitate it to have more choices in acquiring appropriate structures to meet institutional forces (Covaleski \& Dirsmith, 1988; DiMaggio, 1988). In other words, organisations can be more active in adopting "interest seeking organisational behaviour", and hence, to have more leeway in choosing the structures (Oliver, 1991, p. 146). For example, to deal with strategic contingencies, organisations will tend to reflect the complexity of environmental components (i.e., the prominent aspects) into their own structures (Scott, 1987). Oliver thus implies that even organisations operating within the same institutional context may deliberately acquire and retain differing sets of structures.

The way that organisations deliberately adopt certain structures is driven by how they themselves perceive and adopt the structures for more efficient use of organisational resources (Scott, 1987). Strategically, the Knowledge-Based View (KBV) conjectures that organisations achieve competitiveness by sustaining dynamism and continuity of knowledge creation (Nonaka, Toyama, \& Nagata, 2000). For instance, for large organisations, particularly global management consultancy firms, the ability to continuously push content "in context" is a must (Ezingeard, Leigh, \& Chandler-Wilde, 2000). Given the recent unprecedented growth in volumes of data and information and the continuously evolving variety of technology architecture, a sense of (dynamically updated) business outcomes and an awareness of individual knowledge needs could help determine what information should be created and pushed to the right users in a timely fashion (Ezingeard et al., 2000; Malhotra, 2005). Additionally an organisation can opt for the structures that reflect the organisation's history and experience (Powell \& DiMaggio, 1991), and management and user interests for certainty and stability (Oliver, 1991). For example, organisations develop certain ways to solve recurring problems of the knowledge portal; i.e., being overloaded with "unprocessed data and processed information" (Malhotra, 2005, p. 10), and over time these solutions become part of organisational routines.

\subsection{Institutional effects in professional service firms: prominent features}

The research setting of our study is a professional service firm. Our reading of the literature of institutional effects in professional service organisations has prompted us to go further by looking closely at the prominent features of the institutionalised professional context. Particularly, in view of the scope of our study (e.g. knowledge work practices and processes), we found an interesting study of Robertson, Scarbrough, and Swan (2003) that shows the relationship between the institutional effects and how knowledge work practices were identified and evolved. Specifically Robertson et al. identify those features that are considered most likely to impact upon the knowledge creation processes, and ultimately the requests for changing knowledge work practices in consultancy firms. Their study provided us with additional insights into the context of and rationale for how knowledge work practices emerge and are acknowledged in the communities and across the organisation.

For instance, one feature of the institutionalised professional context is the epistemological base of the profession. Regarding the scope of this study - knowledge management, this feature has some significant implications for knowledge creating practices and processes (Halliday, 1985; Knorr-Cetina, 1999; Macdonald, 1995). For instance, Halliday (1985) identifies differences in terms of methodology for producing findings between the scientific professions (engineering and natural science), normative professions (business, management and law), and syncretic professions (the military and academia). While the scientific professions are all based on facts and figures to make judgements and the normative professions depend primarily on value to make judgements, the syncretic professions rely on a combination of both scientific and normative foundations. This implies that the ways in which knowledge is created and consequently legitimised across different institutional contexts vary.

The broad epistemological differences are found not only between professions, but also among different specialisms within a broad professional field (Drazin, 1990). This means across different professions such as the law and science and across different scientific specialisms, distinctive 'epistemic cultures' can be found (Knorr-Cetina, 1999). Knorr-Cetina's 'epistemic cultures' refers to 'those amalgams of arrangements and mechanisms..., which, in a given field, make up how we know what we know' (1999: 1). These epistemic cultures that support how people create new knowledge are characterised by different social, discursive and material practices. Such practices include multiple levels of interaction with natural objects and different sign systems (Robertson et al., 2003). For instance, interactions between competing professional groups and the emergence of distinctive specialisms create specific institutional effects on how knowledge is created and legitimised (Abbott, 1988). In considering the institutional influences on the knowledge creation processes, an organisation should be aware of what may be distinctive epistemic cultures in its environment (Robertson et al., 2003).

Another feature is about the formation of professional identity. Professional identity accommodates attributes, beliefs, values, motives, and experiences in terms of which people define themselves in a professional role (Schein, 1978). In an organisational context, professional identity is seen to evolve interactively with role change (Ashforth \& Saks, 1995). In other words, the influence of professional context on identity is reflected in how knowledge workers differentiate themselves from others and in their role expectations and behaviours.

Specifically, how institutional influences interact and grow together with organisational strategies is illustrated via a method whereby professional identity plays its role in the knowledge creation process (Robertson et al., 2003). Social identity is seen to link with various institutional effects operating to produce a range of competing identities (Alvesson, 2000; Robertson \& Swan, 2003). For example, in Robertson's et al. (2003) study, employees reconciled multiple competing identities (e.g., as professionals such as consultants and as organisational members) and this phenomenon of reconciliation subsequently mediated their behavioural norms. It is thus suggested that how identities combine and compete plays an important mediating role in understanding the institutional influences on the knowledge creation processes in professional service organisations (Robertson et al., 2003). 


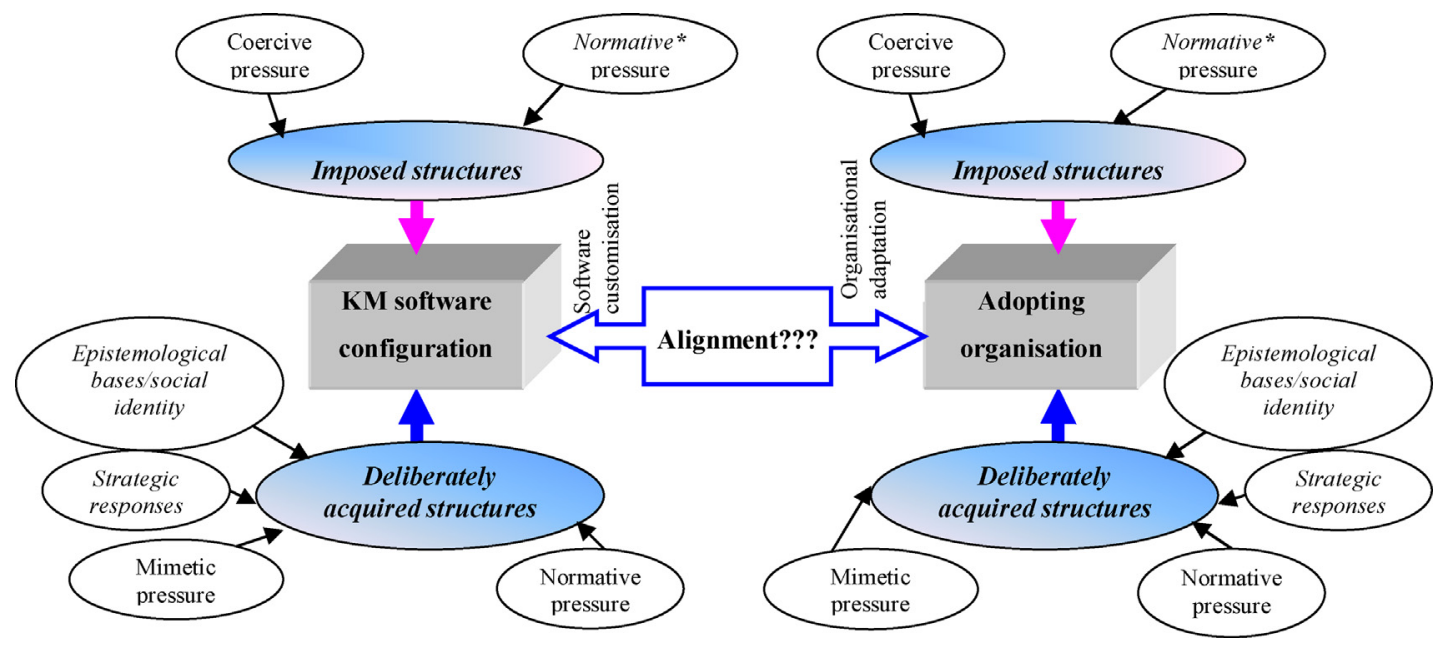

Fig. 1. The likely misalignments between KM software and the adopting organisation.

\section{Research framework and methodology}

\subsection{Research framework}

Our literature review has suggested that the likely misalignments of institutional context between KM software and the adopting organisation can be conceptualised as in the Fig. 1. What is worth highlighting in this study is that we concur with research models suggested by Soh and Sia (2004), but we propose that two noteworthy elements be incorporated into their framework to better understand the phenomenon of KM technology adoption in organisations. First, we acknowledge the existence of normative and mimetic pressures, which we believe are important for our case firm (within its industry) with due consideration of knowledge management feature. ${ }^{3}$ These institutional pressures are in effect not explicitly mentioned by the above-mentioned authors. Second, we suggest considering the impacts of prominent features of institutionalised professional context such as epistemological bases and social identities. We therefore arrive at the research framework in Fig. 1.

Our case company divided its KM technology implementation project into four phases. Phase I, the preparation phase, involved gathering and defining the business case and solution constraints. Phase II, the pilot phase, included adopting activities in some selected sites across the company. Phase III, the implementation phase, involved getting the system and users to be in normal operation after the system's roll-out. Phase IV, the final phase, continues from normal operation until the system is replaced by an upgrade or a different system. When we first approached the KM group, this company was near the end of phase II. Each of these time phases occurs in sequence with no time lags in between the phase.

\subsection{Research methodology}

This study employs a case study strategy (Yin, 1994) to investigate the likely misalignments between KM software and the implementing organisation. Here we are investigating a contemporary phenomenon within its real-life context, especially when the boundaries between phenomenon and context are not clearly evident (Yin, 1994).

\footnotetext{
${ }^{3}$ More discussion on the impacts of these pressures on KM technology implementation will be presented in Section 5 .
}

We analysed the Change Request Forms (CRFs) submitted by the organisation from phase I to III to identify instances of misalignments. To exclude instances of minor or trivial misalignments only those reviewed and accepted by the KM team and recorded in the standardised CRFs were analysed. The KM team uses CRFs to decide whether to adapt or customise the portal. The CRFs typically contained a request for changing a certain feature of the KM software package or for adding further functionality, and as such represented a distinct opportunity for us to study potential misalignments between the proposed software and organisational requirements and practices. Following this analysis, semi-structured interviews were used to confirm and further clarify the contexts and rationale of identified and potential misalignments. We were in the field for 11 months (including 8 months after the system's roll-out) understanding the company's business processes, reviewing the KM system and documentation (e.g., the portal, company's documents, contracts, project files, meeting minutes, requirements analysis, and issues logs), and interviewing 19 key internal stakeholders to gain insights from many different perspectives including the KM programme manager, KM roll-out project managers, content managers, IT/IS experts, senior consultants across the services sectors, and two vendor's representatives. What was especially convenient for our data collection on the portal acquisition and installation is that this case company itself is also a strategic partner of the KM technology vendor. Additionally, informal meetings formed further sources of data gathering. Care was taken, for example, using the triangulation technique, to consider all pertinent case evidence to reduce the risk of research bias. Contextual data that further explain the observations made were taken into account (Klein \& Myers, 1999). This contextual data, which is about the social and historical background of Infoteka, helps us to reflect on how the misalignments emerged. Each interview lasted between $45 \mathrm{~min}$ and $2 \mathrm{~h}$ and $15 \mathrm{~min}$ and was then transcribed and checked with interviewees for accuracy. The interviews were analysed to identify the sources of misalignments (see e.g., Miles \& Huberman, 1994). The conceptual framework is used to examine the data, and to consider some 'what if' questions arising from problems reported by the interviewees or anticipated during the case. Findings were also discussed with two industry experts with rich experience of KM implementation. Some instances related to technical or interface issues were not considered. We therefore arrived at a total number of 42 instances of misalignments, of which there are 4 instances of imposed institutional context and 38 instances of deliberately acquired institutional context. 
For this study, our data analyses were iterative, with each cycle of analysis probing deeper into the data. Such an iterative analysis was important as each time we moved to the next cycle, our understanding of the issue was better refined. For instance, we moved from a simple 'exposed' identification of the misalignments towards uncovering the 'situated' knowledge work context underlying the misalignments, through successive iterations aimed at peeling back the layers of meaning. We identified all instances of misalignments by reading through the KM group's meeting minutes, interviews' transcripts, issue logs, video recordings of the negotiations of the Change Control Board, and CRFs. The output from this first phase was a list of key issues, for instance, managing and collaborating in workspaces, ease of use, managing content lifecycle (searching and sharing, archiving and storing, producing and using content) and accessibility control.

After piecing together all of the information regarding a misalignment, we then attempted to understand the underlying rationale that led to the problem through a process of reflection. Such probing was helpful in moving us towards the deeper, structural reasons for misalignment. This probing often required us to consciously ask ourselves a series of 'why' or 'what if questions, e.g., Why do the users need such a feature? What would happen or what are the consequences if such a requirement is not addressed by the package? Why is the feature/structure not incorporated into the package? What are the vendors' assumptions here in this instance? Was the vendor aware of the requirements of the market or industry? Where necessary, brief follow-up discussions were arranged with a member of KM group or a vendor's consultant for clarification.

\section{Findings}

\subsection{Case company's profile}

Infoteka $a^{4}$ ( pseudonym), headquartered in Europe and in 2007 ranked within the world's top 20 companies in terms of revenues, is a global IT-Management consultancy firm and employs tens of thousands of people in over 30 countries. Infoteka provides business consulting, systems integration, and IT and business process outsourcing services across diverse markets including telecoms and media (T\&M), financial services (FS), energy and utilities (E\&U), industry, distribution and transport (IDT), space and defence (S\&D), and the public $(\mathrm{P})$ sector. For nearly five decades Infoteka's services have been instrumental to the operation of hundreds of orbiting satellites; the handling of more than half the world's foreign currency exchange traffic; processing over US\$100 billion of salaries annually for payroll departments worldwide, and more than $35 \%$ of the world's text messages (SMS \& MMS). In the past decade, Infoteka pursued an ambitious merger and acquisition strategy in the search for growth. Specifically, this firm carried out a series of acquisitions in Portugal, Spain, France, Holland, Germany, Sweden, Australia, and the US. The company formally launched its KM initiative in 2006 although it had used portal technology since mid 2003. From late 2006, the company decided to migrate onto the latest version of the portal technologies with many enhanced features and a new design. The company's portal is organised into three environments: My Information, ${ }^{5}$. Workspaces ${ }^{6}$ and Our

\footnotetext{
4 The name of the case company has been anonymised as per the agreement between the researchers and the KM group manager.

${ }^{5}$ My Information provides private and shared information relating to each staff.

${ }^{6}$ Workspaces are web-based environments that enable teams to share and collaborate on information.
}

Knowledge. ${ }^{7}$ This organisation was chosen based on a combination of accessibility and representativeness: Infoteka is a global consulting firm, which is commonly discussed as the archetype of knowledge-intensive firms consisting of multiple communities of practice (CoPs) (Alvesson, 1993); Infoteka has implemented its KM initiative and the knowledge portal in a substantial way; Infoteka has a large-scale portal implementation in terms of its user base; Infoteka's global operational context (i.e., the corporate-level and local-level company and different service sectors) presents interesting issues of portal-organisation alignment; e.g., diversity in deliberately choosing work structures.

\subsection{Findings}

\subsubsection{Imposed structure misalignments}

This section will proceed as follows. For each misalignment instance, we will introduce the current/emergent ${ }^{8}$ knowledge work context and practice of Infoteka and explain how such context and practice were not supported by the existing functions of KM software. We then elaborate the sources of such differences from the institutional theory perspective.

Overall, our analysis suggested that the imposed misalignments can be categorised into two parts. The first relates to coercive pressures such as the nation-authorities. The second relates to the contextual differences in industry. Specifically, in accordance with our research framework, we found 4 instances of imposed structure misalignments. Of these 4 instances, 2 arose due to countries' regulations and rules. All instances were found mainly in phase II.

The low number of imposed misalignment instances due to coercive and normative pressures can be explained by the fact that this consultancy organisation is not in a highly regulated domain like those in financial, health-care or legal services. The two instances are: (I) governmental policies on privacy and data protection; and (II) governmental rules on working with projects in the space and defence industry.

As far as the resolutions for these misalignments are concerned, our analysis showed that this global organisation responded to most misalignments by modifying the work structures embedded in the software package (90\%). Infoteka decided to adapt itself to the software package in only a handful of instances, and these were typically related to the irregular requirements of clients and the functionalities were usually partially fulfilled by the software package.

4.2.1.1. Coercive pressures. The first part of imposed institutional structure misalignments caused by normative pressures relates to the coercive pressures by governments. These may be classified into issues with regard to governmental policies of data protection and government rules for working with projects in the space and defence industries.

4.2.1.1.1. Governmental policies of data protection. We found a misalignment theme related to protecting data. France, Germany, and Italy are very restrictive over what information an organisation can hold about a person, and to where the organisation stores and sends that information. In a KM scheme this kind of information is crucial for locating and connecting experts given the global operational context of this consultancy firm. The portal initially supported a practice of holding personal information as follows: If a consultant working on a project of the E\&U sector was struggling to find the solution for data transmission of an oil field in

\footnotetext{
7 Our Knowledge is a central store of publications, shared with all company staff. The information is stored in knowledge areas by subjects, such as sales and marketing and market intelligence.

8 The word 'current' or 'emergent' means at the time of our study.
} 
South America, he would first, as advised by the KM group, look on the My Information (MI) environment to find out who is most knowledgeable and experienced about such technology in the E\&U sector. Typing certain keywords in the search engine, this consultant would find who used to do similar projects or for the same clients. Then, such information would be retrieved and stored in his MI environment (KM group - Log of Change Request Forms, 2007). A senior consultant in France illustrated the situation:

"The MI environment offers plenty of things for individuals. For example, people can change or update their profiles, customise [incoming] corporate news alerts, search, copy, and disseminate information about experts...That is to say, our users now have more freedom [than what they could do with the previous version of the portal]. A common practice within our user community is to use [the] profiles of these experts who have the skills, interests, and expertise suitable for our project, [and then] put it [the information] somewhere for easy access, or send it via IM [Instant Messenger] to other people [in another country]... The problem is that [so far] we haven't controlled [such practices]... Why? For consultants residing in France, Germany and Italy, they have to be very careful about what they can store [in the MI environment] about a person"(Frans, senior consultant in FS in France, 22 May 2008).

The misalignment arose during the pilot projects in France and Germany because as the portal was developed in the North American context, it was designed to support users to freely store and send any information about experts. To tackle this problem, there was a request to modify the above mentioned existing work structures of holding and sharing information of experts in the MI environment. Specifically, a new mechanism was suggested to make sure that information about experts could be stored properly. Under this correction, only certain information could be shared (e.g., who possess what skills? Who used to do that project?). To get the information staff must go through a scanning process that would automatically review their role and status related to their project (KM group - Log of Change Request Forms, 2007; Meeting minutes - Adams, 2007). To resolve this misalignment, the KM group decided to customise the software product.

4.2.1.1.2. Governmental rules on working with projects in the space and defence $(S E D)$ industry. As $S \& D$ projects' nature is quite 'sensitive', according to UK regulations, every action must be performed on workspaces set up for given groups and monitored so that authorised supervisors know what is going on (KM group - Log of Change Request Forms, 2007). Specifically, to comply with governmental rules, there were requests to create a group of functions to enable 'monitoring' of all actions occurring in the workspaces in real-time. The problem, which was identified before the pilot project, was explained by a KM roll-out project manager in Germany:

"By 2000, we did not have many [space and defence] projects...From late 2002 [to the present], we have done many projects for the European Union, particularly for the UK government. . . After the '9-11', many things [in relation to information security] have been changed. . For example, for [SED] projects, according to the UK laws, we are required to monitor all activities in the workspaces, for example how consultants pull and push data and information, how they collaborate with others to process data or how and where they send the content to. All data and information related to [or used in] the projects can not be seen in the search engine... They [the government] said that this is for national security"(Engel, senior consultant in the TEM, 9 May 2008).

While the vendor's representative reflected:

"Actually we received similar requests from clients in Scotland and Northern Ireland some time ago, and [their] requirements were also [for the] aerospace and defence projects...The requirements [for monitoring the workspaces] are getting more complex, and so we need to provide them with more sophisticated tools [to do]. . I can tell you that [my company] can anticipate certain changes based on our experiences. . .but this market [space and defence] is quite unique, I mean, it needs the tools to process and monitor sensitive content. You may never know exactly what they [clients] want you to do [change the practice] in the near future" (Partel, vendor's representative, 12 Mar 2008).

Misalignment arose because the portal was incapable of monitoring all the knowledge work practices in the workspaces (KM group - Log of Change Request Forms, 2007). To resolve this misalignment, the KM group decided to modify the software.

4.2.1.2. Contextual differences. The second part of imposed institutional structure misalignments caused by normative pressures relates to contextual differences in industry. Such differences can be classified into issues with regard to the inter-relationships of firmsupplier and firm-customer. Two instances were found: (I) pressure for new content innovation in the Telecom and Media industries (T\&M) and (II) requirements for publishing and distributing content for clients in the legal sector.

4.2.1.2.1. Pressure for new content innovation in the TEM. The quest to continually provide a new and diversified range of content (i.e., image, audio, and video files) for clients creates pressure around the fast-moving telecom and media (T\&M) industry (Infoteka Brochure Spring, 2007). Consider the market for 3G phones in the European market. Given the strong technological evolution of mobile telephony communications protocols such as HSDPA $^{9}$ and the launch of new generation mobile phones like the iPhone 3GS recently, the need for both downloading and uploading audio and video files is high, and, thus, prompts the need to continually provide services to clients in the T\&M sector. To understand international clients' ever-changing and diversified demands, it is crucial for Infoteka to work closely with information service providers, such as Gartner, Butler, and Factiva. To connect with these suppliers, Infoteka's portal must satisfy particular standards imposed by them (Infoteka - Issue logs of KM group, 2008). This problem, which was raised in the implementation process, was further commented on by a senior consultant in the T\&M sector:

"There's a need to change the configuration of our workspaces; Because if we don't, we may have some problems when exchanging and sharing content with Gartner...The IT guys [of Gartner] explained that they set the same standards for IT service firms to connect to Gartner's portal...It's the rule of the game, you know... We need them, and so we need to accept their practices...We were not ready for this change, I mean, the request for [change] was submitted [to the KM group] two months after [the] roll-out [implementation began]. . .This is because some guys [in the IT department] did not see [this change] as a big deal" (Kross, KM roll-out project manager in the UK, 9 April 2008).

The above-mentioned standards were to protect the integrity of content shared between Infoteka and its suppliers. More specifically content would be supplied by Gartner in a standardised form that subsequently required Infoteka to modify its workspaces. Such supplier-imposed practices mean that the portal should be embedded with work structures to automatically collect only

\footnotetext{
${ }^{9}$ High-Speed Downlink Packet Access (HSDPA) is a 3G (third generation) mobile telephony communications protocol in the High-Speed Packet Access (HSPA) family, which allows networks based on Universal Mobile Telecommunications System (UMTS) to have higher data transfer speeds and capacity.
} 
standardised content sent from suppliers and then send to the 'right' consultants. Misalignment arose, since the imposed standards were not supported by the portal (KM group - Log of Change Request Forms, 2007 and 2008). The final resolution was modifying the portal.

4.2.1.2.2. Requirements for publishing and distributing content in the legal sector. A few clients in the public and legal sector in Thailand and Japan required that before sending documents extracted from the workspaces to them, Infoteka must check whether the materials follow specific requirements in terms of confidentiality and style set by them. This is because these clients would then distribute the documents to their partners in some legal networks (Infoteka - Issue logs of service team, 2008). A senior consultant in the public sector explained the problem, which was exposed during the implementation project:

"Thailand $A B C$ [a public organisation] has been one of our [Asian] clients for over two years. The manager of this [public] organisation is very keen on KM and this organisation has won many [industry] awards for its success in managing knowledge. They have established several standards [of producing and delivering content] for firms like Infoteka... Other firms in Japan also sent [similar] requests to us...We are well aware of such issues [of confidentiality and style] and deal with [them] seriously...We know that they [clients] need to save money. However, our view is that [their] requirements are not that common" (Schoen, KM roll-out project manager in Holland, 16 April 2008).

In terms of confidentiality, every document must go through a process, whereby the level of 'confidentiality' of each document would be automatically assessed against a pre-defined framework based on the appearance of keywords and meta-data. There are four levels of confidentiality including 'low', 'medium', 'high' and 'top,' each of which requires a style to adopt. For style, content in a document must be arranged in accordance with a pre-defined format. Infoteka was therefore required to integrate such a process into the workspace to produce materials that comply with clients' needs. If Infoteka decided to address these requirements, it would have to modify the portal and the ECM (Enterprise Content Management) package. In other words, misalignment arose because the software package was not embedded with the required work structures to support this procedure (KM group - Log of Change Request Forms, 2007 and 2008). The final resolution was an organisational adaptation to the package as the requested practices were infrequent.

\subsubsection{Deliberately acquired structure misalignments}

In the previous section, misalignments arose because the external authorities imposed rules and regulations on the case company. In addition to being imposed, this case company, under specific circumstances, also voluntarily acquired and evolved work structures.

We found that most deliberately adopted structural misalignments typically arose from the company's strategic responses to its institutional context. Specifically Infoteka responded to changes in its institutional environment in three ways: (i) reflecting the complexity of environmental elements (i.e. by copying prominent aspects) into Infoteka's work structures, (ii) satisfying management preferences and (iii) satisfying user preferences. In particular not many misalignments arising from mimetic and normative pressures were identified.

There are total 38 misalignment instances that were largely found in phase III. Only a few were identified in phase I and II. Similar to the imposed structure misalignments, a high proportion of misalignment (93\%) resulted in customising the KM software package. In only a handful of cases, the KM group agreed to adapt its knowledge works to the software package instead.
Our presentation proceeds as follows: For each misalignment theme, ${ }^{10}$ we first introduce the initial work context/business environment of Infoteka. We then emphasise the changes in work context/business environment to highlight how such changes caused misalignments.

4.2.2.1. Reflecting the complexity of environmental elements into Infoteka's work structures. In responding strategically to changes of institutional context, this KM software adopter attempted to copy important features of the complex changes of its (local) operational environment. Specifically Infoteka's strategic move results in a set of instances, which consist of two key themes. For the first theme, for instance, a KM coordinator in Sweden explained why the KM group must re-configure its portal to change the library hierarchy by expanding the content stores (i.e., containing project summaries, customer references, and sales and marketing documents) of the Our Knowledge environment:

"Within [the] Our Knowledge [environment], we have a hierarchy of sites and within those sites, we have a number of document libraries. That's how we organise storage for key publication. . As part of the collateral programme, we are now working with people in SWK (pseudonym). SWK is a Nordic-based company that we acquired two years ago [2006]. This is a large firm with about 9 thousand staff members. We [Infoteka] want to get everything they [SWK] have such as Sales and bids and get the stuff translated [into English]. I mean, we plan to change the number of libraries within Our Knowledge to hold the content and propose a structure for doing that. . .Regarding the meeting minutes that you just showed me, I agree with some people in the KM group that such changes in our operation and business at the local level [in Sweden] must be 'seen' at the corporate level [in terms of our portal]; Otherwise we could be in deep trouble" (Crombaker, senior consultant in EEU, 17 April 2008).

\section{While the vendor's representative reflected:}

"The initial design could accommodate all the content stores within the [Our Knowledge] environment. Normally, our clients just use the [library] system and they do not need any [changes]. Now, for Infoteka, this [request] is because they acquired new companies...Well, they did not mention about this [expanding content stores] when they built [their] business cases...They should have informed us of the potential changes [like this] much earlier, for example, in the pilot phase in the Nordic countries and Brazil. This [could] help save cost and time for both parties...We need several months to analyse and implement [the requested changes]. Modifying the library [hierarchy] was not easy" (Green, vendor's representative, 29 Nov 2007).

To facilitate Infoteka's new Swedish operation, consultants wanted to create 7 new libraries including: financial services; industry, distribution and transport; public and healthcare; utilities and telecom; cross industry solutions; integration and application centres. By creating these new libraries, the local organisation (i.e., the lines of business in Sweden) could be reflected in the portal to better support the Sweden-based collateral coordinators to upload documents to the Our Knowledge environment. This approach, which was raised during the implementation project, would therefore help simplify the procedure of uploading documents and of requesting area ownership ${ }^{11}$ for Sweden. Further, the requests also aimed at enhancing Infoteka's knowledge asset integrity. Since

\footnotetext{
10 Each misalignment theme represents a group of instances.

11 In the Our Knowledge environment, to be able to upload to a specific area, the content owners must go through several steps to register for ownership of this area.
} 
this approach ${ }^{12}$ sought a radical change in how staff upload and store content within the Our Knowledge environment, the portal's configuration and functions needed to be re-designed. Otherwise, misalignment could occur and, thus, adversely affect Infoteka's centralisation of publication. The final resolution was that the vendor agreed to change the portal's configuration (KM group - Log of Change Request Forms, 2007; Infoteka - Issue logs of service team, 2007).

Similarly, regarding the second theme, because of the company's recent acquisition of a Spanish telecom service firm, there were requests to change the library hierarchy (e.g., increasing the number of libraries to include: financial services; industry, distribution and transport; public and legal; and telecoms and media) within the existing Our Knowledge environment (KM group - Log of Change Request Forms, 2008). By changing in this way, content managers as well as consultants in Spain believed that they could upload more documents of sale and bid projects to the Our Knowledge environment. Additionally, their requested approach could also enable the integration of the KM systems across the global firm. Resembling the misalignment relating to the Swedish operation mentioned above, the KM group decided that the vendor should re-design the portal (Meeting minutes - Adams, 2008).

4.2.2.2. Satisfying management preferences: upgrading reporting functions. Misalignment instances relating to strategic response to the external business environment also point to the interest of management. This means Infoteka attempted to find ways to satisfy managers' requirements for a better knowledge work performance. There were various themes that touch upon local management of workspaces' metadata and permission for access or enabling content sharing, archiving and re-using; e.g., automatic importing of content from an external party (i.e., Ovum or Sitsi) into the Our Knowledge environment; assisting the archiving mechanism; enhancing the update tool for projects' metadata, supporting the knowledge reviewing process in the Workspace environment, and enhancing the reporting function in the Our Knowledge and the Workspace environments (KM group - Log of Change Request Forms, 2007 and 2008; Infoteka - Issue logs of KM group, 2008). To illustrate, let us focus on two typical misalignment themes: enhancing the reporting function in the Our Knowledge and the Workspace environments.

For example, during the implementation project, many content managers in Bangalore (India), France, and the UK identified that within the Our Knowledge environment there is a lack of reporting on: (i) who contributes what document and the frequency of contribution; and (ii) the number of staff that download a specific document and the frequency of downloading. They therefore requested that the reporting function be upgraded to address these deficiencies. They believed that having access to information related to item 2 could help them manage the content of the Our Knowledge environment better by evaluating its quality via the usefulness of a document. Further, having information related to item 1 could help provide the HR department with statistical figures, which could be integrated with other Knowledge Performance Indicators (KPI). KPIs are in fact an indispensable part of the Career Pathway scheme of every individual in Infoteka (KM group - Log of Change Request Forms, 2007 and 2008). The context was clarified by the KM programme manager:

"One of the key things is to provide them [with] the feedback in terms of what is actually happening. If we ask the Marketing department in a country to do something, then we need to show them

\footnotetext{
12 Creating new content stores means that this company must change its practice of uploading and storing content at the local level.
}

what they have actually achieved so far and give them some targets, for example, and allow them to compare how they are doing [in relation to] another company in other parts of business...So, we will know how much content is being provided by each part of the business and what the usage level is like...In other words, there are two sides. One is [that] we want to have reporting on what is in there [Our Knowledge]. The other is [that] we want to have reporting on what has been taken out. That means we have the publication side and the usage side" (KM programme manager, 28 Mar 2008).

Since the requests were not supported by the initial design of the portal, misalignment, thus, arose (Infoteka - Issue logs of KM group, 2008). For this misalignment, the KM group decided that the vendor should incorporate additional work structures to assist its managers in doing their knowledge work.

With regards to another misalignment theme, requests for embedding additional work structures in the Workspace environment aimed at helping content managers and KM coordinators to include more data fields in the report by specifying them in advance (KM group - Log of Change Request Forms, 2007). Upon completion of a project, content managers and especially the HR department need to know how individuals and teams across countries collaborate, share, and distribute knowledge during their projects. Specifically they need to measure (i) how many documents individuals and teams have shared as well as (ii) how many times a specific document has been (re)used and updated. For the HR department, the reports on the first target could contribute to the Rewards and Recognition or the Career Pathways scheme to motivate both teams and individuals to engage more in the KM initiative (Infoteka - Issue logs, 2007). For the service team in Bangalore and Infoteka's content managers, the reports on the second target could help them to evaluate the usefulness of a document to better manage its lifecycle (e.g., keep on updating or go for archiving). Misalignment arose because such requests were not supported by the KM software (KM group - Log of Change Request Forms, 2007). Similar to the above-mentioned misalignment referring to reporting functions in the Our Knowledge environment, the KM group also decided that the vendor should incorporate additional work structures to assist its staff in capturing the required information.

4.2.2.3. Satisfying user preferences: searching and grouping in content type. Besides satisfying management preferences, we also found that this global company with its large and diverse user base attempted to deliberately acquire and evolve work structures to meet its user interests of enhancing knowledge work performance. This point was made by a KM coordinator in the US:

"Since we have people with different cultures and backgrounds, satisfying their [common] preferences and the local-level [requirements for working conditions] is important to ensure a powerful global delivery capability for our clients" (Zaynes, IT professional, 25 Sept 2008).

Within this category (satisfying user preferences), we found different themes that facilitate users to extract content such as adopting a tree-shape type of navigation in the Our Knowledge environment; tuning up search relevance based on metrics of document usage; customising the Our Knowledge environment by allowing self-setting of preferences; and performing live search and further filtering of the search results in both the Workspace and Our Knowledge environments.

For example, there is a prominent theme relating to searching and grouping in content type in the data. Given the nature of work and project, many users favoured searching and grouping results by content types (i.e., brochure, project summaries, and references) and languages in the Our Knowledge environment as 
they believed content type would be important for refining what they are looking for. More importantly, the retrieval process could be more productive and accurate when knowledge items can be grouped and displayed in content types (KM group - Log of Change Request Forms, 2006, 2007 and 2008) (see Figs. 2 and 3 below). This was exemplified by a KM coordinator in the US:

"With the current search function, for example, if you are doing a report for the marketing department and type ' $3 G$ broadband services' to search for customer references on this issue, what you see will make you very confused. You have to open and read every single document [project summaries, brochures, lessons learned and references] in there to find out if it is the one you want... How can you make a report to the line manager this afternoon if you have to spend at least 2-3 h searching Our Knowledge [environment] for the 'right' documents?. . This is not the practice that our user community expect [to see]. Global companies like us create gigabytes of data and information everyday. This won't work! [This is] one of the biggest problems of this portal...We have discussed with users on

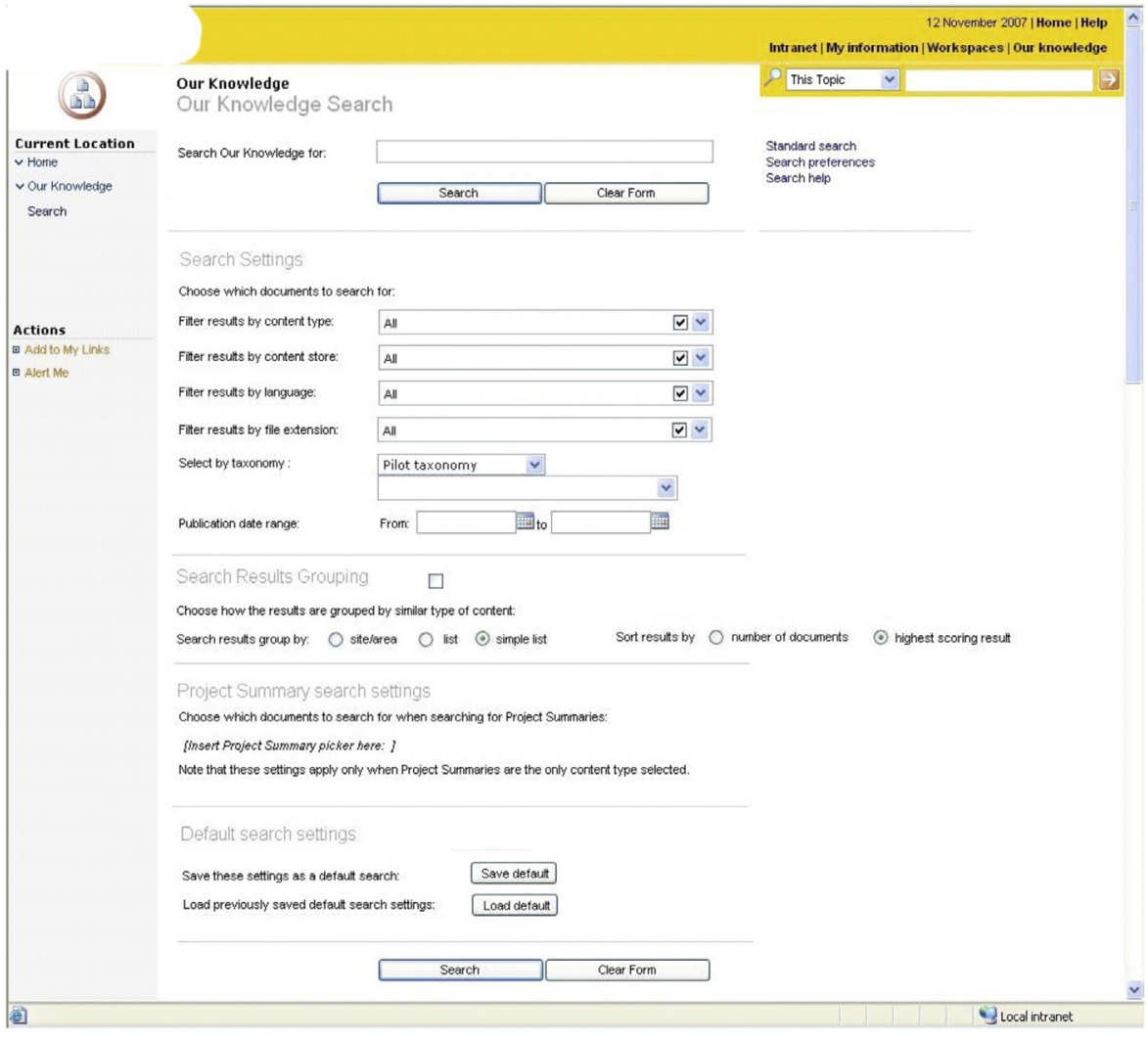

Fig. 2. User interface for searching by content types.

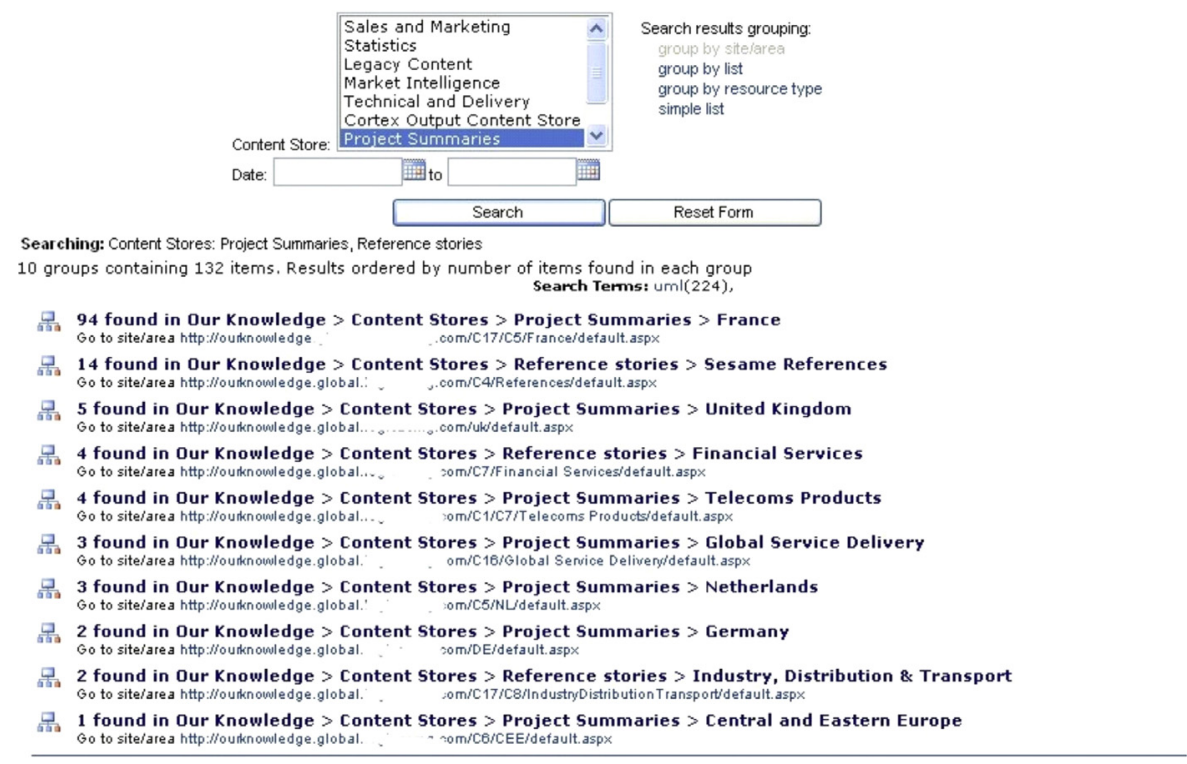

Fig. 3. User interface of grouping search results in content type. 
several occasions to find out what they want and what it [the search function] should be. Now, what you see today is that all [search] items are grouped and displayed in either project summaries or references. . . and we even do more. On the first page [of the search results], we provide them with 'best bet' [function] to assist them in finding relevant things faster...Our experts actually identified this limitation [of the search function] in the pilot projects, but we decided to put [it] on hold until [the project] roll-out. This is a very big change. We wanted to give more time for our staff to reflect on how they use [it]" (Zaynes, IT professional, 25 Sept 2008).

Within Infoteka, it is understandable that individuals and groups have differing needs for knowledge items related to their work. Without the ability to filter search results by content type, it would be more time consuming for users to extract the 'right' content from the Our Knowledge environment. From a Knowledge-Based View (see for example Section 2.2), this requested practice related to the speed of pulling the knowledge items for knowledge workers. Each document contained within Our Knowledge has a number of attributes such as language, service sector, taxonomy (how the document is categorised and stored), content store, content type (e.g., project summary, lessons learned, or customer reference) and publication date. Therefore, reviewing all these attributes to find the most appropriate document would not be easy. ${ }^{13}$

For instance, staff working on a Customer Relationship Management project for clients in public transportation in France may need to know about sales of tickets, brochures, or case studies on customer services in transportation in both English and French. Alternatively, those who work on projects for clients in telecoms and media industry in Finland would need to have content produced by the global service team such as lessons learned or examples in Finnish to gain further insights into their work. Instead of reading all the hits returned, this requested change could help bring only those documents containing relevant items that users could be interested in (See Fig. 2).

Misalignments arose in this case, as the search engine did not enable staff to search and group the results in content types (Meeting minutes - Adams, 2008; Meeting minutes - Key, 2008). To improve individual and group's productivity, the KM group decided that the vendor should change the work structures within the search engine of the portal (KM group - Log of Change Request Forms, 2007 and 2008).

4.2.2.4. Satisfying user preferences: facilitating users in working with the Our Knowledge environment. Assisting users to pull out content effectively from the Our Knowledge environment is a high priority of the KM group. This issue was repeatedly mentioned during actual implementation as it was identified that many consultants were not well aware of useful content in the Our Knowledge environment. There is a set of misalignment instances, whereby members of the KM group wanted to change the configuration of the portal to (i) make the Our Knowledge environment more organised and accessible to meet a wide variety of knowledge seeking tasks; (ii) facilitate users to specify the task they want to do by prompting dialogues, and (iii) help users navigate to where they want to be (KM group - Log of Change Request Forms, 2008). As a KM coordinator in the US explained:

"I think our [KM] group has done the job fantastically. We have organised Our Knowledge environment in a very good

\footnotetext{
13 By using the default search engine, we tried searching project summaries of Intelligence Transport Systems in Holland and Singapore and found that there were 109 hits (with different attributes) on this issue. To find the most appropriate document, consultants need to have in-depth experience included in the project summary to save reading time.
}

way... However, the outcome [of organising and storing key publications in Our Knowledge environment] is good from a developer's view, [but] not from a user view. I am talking about the way this [environment] guides users to do their work. I've received a dozen emails a month from my colleagues around the world [to] question about the possibility of telling them what is stored inside. This is a real challenge for our KM initiative as normally people could not be aware of what they know or what they should know, and [eventually] the existence of certain publications valuable for their work" (Zaynes, IT professional and KM coordinator in USA, 25 Sep 2008).

Specifically, according to the requests, when accessing Our Knowledge environment, users would then be asked by a banner, "What do you want to do?" with a drop-down menu consisting of a list of typical knowledge seeking tasks. Depending on which task the user selects, a customised page would then be displayed either with useful links to steer users towards project summaries, case studies, and customer references in order to respond to a capacity question or with a customised search dialogue leading to brochures and presentations if the task is related to sales and marketing (Infoteka - Issue logs of service team, 2008). Misalignment arose as the requested work practices were not supported by the portal. For this misalignment cluster, the KM group decided that the vendor should embed new work structures into the portal to reflect such requested practices (Meeting minutes - Key, 2008).

4.2.2.5. Satisfying user preferences: making business-specific topic page. In addition to pulling out content, assisting users to easily and conveniently push documents into the Our Knowledge environment is also important. From a knowledge-based theory perspective, continuously and dynamically updating content is important to enhancing efficient knowledge use (Nonaka et al., 2000). For example, there was a set of requests, whereby many content managers wanted to assist consultants to self-produce business-specific topic pages, ${ }^{14}$ as these managers believed that such topic pages could add value to the organisation's knowledge assets (KM group - Log of Change Request Forms, 2008; Meeting minutes - Adams, 2008). Indeed, within Infoteka, these content managers' maintained that it would be significant for a user to self-produce any topic pages without necessarily having knowledge of technical intricacies. The context was described by a senior consultant of IDT in the UK:

"The idea came from an HR staff's blog. Based on these [requests], we want to have the criteria to decide how to display the content on the [topic] pages. For example, if I am looking for topic pages on 'automotive', maybe I want to see the automotive case studies listed on that page. . So, we plan to create web-parts based on resource types, case studies, and markets such as IDT, Telco [Telecoms and Media] or EEU. So, [if] you decide the search criteria and when you display the page, you will see the results picked out from the content stores. Simply put, what we want to do is to provide more user configuration by asking 'what they want' and by selecting more options or something like that. Then, that [their specification and preferences] would automatically 'go' to the web-parts to display your topic page. I mean [you] don't have to be an IT guy to do [the] job" (Hobster, assistant to KM manager, 30 Oct 2007).

\footnotetext{
14 Business-specific topic page: This page is to provide users with both common (i.e. definitions and examples) and in-depth knowledge (i.e., the search results including capability statements, fact-sheets and brochures, or case studies) about a particular operating business function. Based on users' pre-defined practices, the web-parts play the role of exacting these contents from common content stores to display in the topic pages. An example is the topic page Intelligence Transport Systems (ITS) (see Fig. 4).
} 


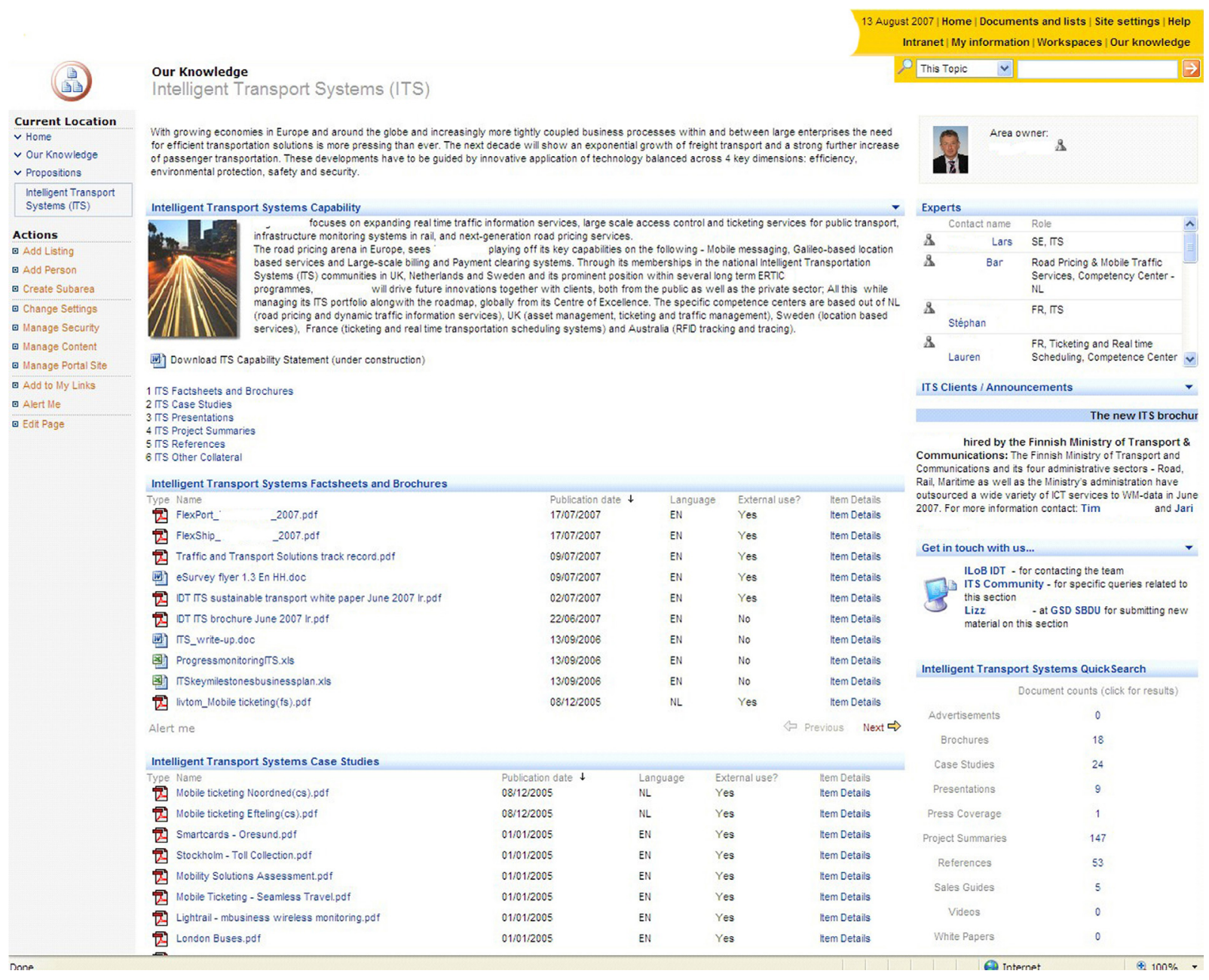

Fig. 4. An example of topic page: intelligence transport systems.

Specifically, central to the requests to self-produce business topic pages were two main stages. In the first stage, users would interact with a series of prompting dialogues in order to decide how their topic pages would appear (i.e., frame styles and states, layout, advanced and custom properties) and to define the search scope where the content would be extracted. In the second stage, users would select options on how the search results would be displayed. An illustration of this topic page is presented in Fig. 4.

The misalignment arose because the requested practices were much more complex than what the portal could support. For instance, users could only produce topic pages once they gain substantial knowledge of web-parts that define how the topic pages should look like as well as the search scope function. The KM group eventually agreed to resolve this misalignment by asking the vendor to incorporate appropriate work structures into the portal to assist users to work under the requested mechanism (KM group Log of Change Request Forms, 2008).

Very few misalignment instances arising from mimetic and normative pressures were exposed. A typical example is the request to facilitate collaboration as well as 'social networking' by embedding special work structures in the portal to enable users to search CVs/Skills in the My Information environment (KM group - Log of Change Request Forms, 2008). This approach was in fact initiated by content managers, who are also active members of the KM association in Bangalore (India). This enhancement allowed users to find experts with particular skills to help them respond to their questions. For instance, if a consultant would like to know who has Java programming skills at an advanced level, by using search CVs/skills, he could find experts with that skill at the level relevant to his work. In addition, in response to questions like: "Who has done projects similar to project XYZ?", or "Who has worked with client/company $A B C$ in Singapore?" or "What experiences/problems did you have with client/company ABC in Singapore?", the search engine could scan CVs of all experts to return 'matching' results. Misalignment arose because such requested practices were not supported by the portal. The KM group decided to implement the request to address this misalignment

\subsubsection{Institutional effects on acquiring and evolving knowledge work practices}

Analysis of the adoption, implementation, and use of a KM software package needs to emphasise 'the complex texture of knowledge' (Knorr-Cetina, 1999, p. 2). This approach helps to better understand the unique aspects of KM software implementation. Moreover, given our review of institutional effects on the knowledge creation process in Section 2.4, we find a connection between the epistemological base and the 'epistemic culture' (Knorr-Cetina, 1999) within the IT or management profession in our research setting. From an institutional theory perspective, by taking strategic responses to the external environment into account, we believe that features of epistemological base and culture and social identity could be helpful to gain further insights into the sources of misalignment as they play a pivotal role in driving an organisation to acquire and evolve certain knowledge work structures for management and 
user interests. Indeed, as we will show in this analysis, such features of institutional context are in effect related to organisational and individual ways of acquiring and enriching knowledge in our research setting.

To illustrate, let us consider two typical themes. The first theme is about searching and grouping in content types. As we observed in the case study company, in each service sector (i.e., T\&M, FS, IDT, $\mathrm{S} \& \mathrm{D}$, or public and legal), the company consults in both IT and management fields that have differing epistemological bases. ${ }^{15}$ These differing epistemological bases help explain in part why users (here represented by consultants) have differing needs for knowledge items for their work. As further clarified by a vendor's representative:

"Well, our system architects did not assume [that] the implementers would have such a need to extract and group the search results into different types. Generally speaking, we can only create a 'common' search function in there, but [we try to] make it flexible for change. According to our design, how implementers get content from the portal is basically the same: specifying the keywords and where to find [the databases]. This is a well-accepted approach in the market...Hmm, I think this company's request for change is quite. .I mean, [organisation] specific. Our requirement analysis showed that this is probably because the company operates in different industries...Oh, one thing, data of management is different from that of IT, if you see what I mean...The KM programme manager told us a few months ago that to create new knowledge more productively, their consultants need to use a search engine to extract only those documents, which have similar properties and attributes [metadata] appropriate for their work. I agree with him [the KM programme manager] that our solution could not work effectively in their work setting. We should help them access [the content] in a more systematic way"(Green, vendor's representative, 29 Nov 2007).

The feature of institutional context such as epistemological base, together with what we analysed in Section 4.2.2, lies at the heart of reasons for the change request. From a KM technology developer perspective, ${ }^{16}$ it could be difficult for them to predict the complexity in terms of extracting a wide variety of knowledge items since they could not be well aware of differences in the epistemological base. More specifically, this unique institutional context with differing service sectors and professions (e.g., including IT and management) is then manifested in the epistemological culture where most consultants are preferably based on content types for processing, thereby adding more value to the projects.

The second misalignment theme touches upon providing more functions for the external workspace environment. Specifically, some projects of the space and defence (S\&D) sector (e.g., Galileo or European Space Agency contracts) involve customers and partners whose locations are distributed throughout Europe. Because of their locations, some consultants ${ }^{17}$ with different assigned managerial roles in projects (e.g., project managers, quality controllers and auditors, or system moderators and maintenance) suggested embedding more work structures into the external workspaces in

\footnotetext{
15 As explained by Halliday (1985), IT as part of a scientific profession relies primarily on judgements of fact and figure, whilst management as part of a normative profession mainly relies on judgements of value. This means that in producing judgements of fact, the IT field employs experimentation, replication, and induction; whilst the management field employs deduction from previous cases and precedents and reinterpretation of existing judgments (Robertson et al., 2003).

${ }^{16}$ From Infoteka's perspective, the intention to search and group the result in content types "was mentioned very early in the implementation project" (KM manager, 28 Mar 2008; Infoteka - Issue logs, 2007).

17 These consultants held different professional roles based on their expertise and experience.
}

order to enhance knowledge creation practices, which could be simultaneously carried out by consultants, customers, and partners. The requested work structures included producing a picture library, contact and event lists, and especially incorporating with a 'brainstorming' board and survey facility (KM group - Log of Change Request Forms, 2007).

This misalignment, in accordance with our conceptual framework, was categorised as a strategic response to the external environment in the interests of both management (represented by the above-mentioned managerial roles) and users (represented by professional roles). In these S\&D projects we observed a deep engagement of clients and partners, whose epistemological bases and their resultant epistemic cultures are varied as these people came from a large pool of professions such as law, engineering, military, or academia. Each profession had its own epistemic culture of producing new knowledge for the projects.

For instance, partners in the legal and public and clients in the management fields preferred creating new knowledge by using the picture gallery. Moreover, Infoteka's consultants, clients and partners in the engineering/IT field would opt for discussion boards. These epistemic cultures are somewhat different from the 'widely acknowledged' epistemic culture in the market, for example, using email and instant messenger applications, assumed by the developer. As commented by a vendor's representative in our interview:

"Regarding this misalignment, we see that this request is significantly subtle, even much more than many [change requests that] we have dealt with. For instance, people requested to be equipped with tools to collaborate in making a picture library or to assist them in brainstorming...Well, this [request] is in fact a combination of requests made by previous customers...They [the customers] have different backgrounds, such as legal, air force, navy or transportation and electrical engineering...We actually spent so much time discussing with the [KM] group. Their justifications [for change] contain many issues representing users' preferences for how they want to do the [knowledge] works in the [external] workspaces effectively" (Partel, vendor's representative, $12 \mathrm{Mar}$ 2008).

Notably, besides differences in epistemological bases, the differences in social identity were also attributable to this misalignment. Indeed, our analyses show that the technological designers were not well aware of and even could not anticipate such a complex social identity (Teo \& Men, 2008). Initially, in designing KM software, the system architects could only target a particular group of users, for example, the consultants or clients who are holding certain organisational roles (i.e., the KM coordinators, KM roll-out project managers, or content managers) and professional identities (e.g., technical consultants and advisors or system advisors). Such groups are what the system architects normally encounter in the market. However, in our case company, the diversity of social identity expanded because of the engagement ${ }^{18}$ of more clients and partners in different professions. On the one hand, based on their own professional identities (assigned by the project manager) and organisational roles (assigned by their own organisations), these people may have differing motives and experiences of doing knowledge works, making it difficult for the system architects to mediate the likely conflicts to obtain the resultant knowledge work structures. On the other hand, the KM group also attempted to reconcile these multiple identities (as professionals, but also as consultants and as organisational members) reflected by the convoluted descriptions (of the request) and justifications in the change request forms (CRFs).

\footnotetext{
18 This engagement of more clients and partners took place after the project had been specified.
} 
To demonstrate such impact of social and professional identities, we offer three typical examples from our data for consideration. For the first example, we re-consider the above-mentioned misalignment theme: adding more functions into the external workspaces. We extract for this purpose parts of the notes and justification recorded in Infoteka's change request forms. For ease of understanding, Chris is a senior consultant in T\&M (professional role) and assistant manager for sales and marketing department (organisational role) in the UK; Richard is a senior consultant in FS (professional role) and responsible for bidding projects of T\&M, IDT and FS (organisational role) in the US market; Sylvia is a content manager for the Nordic market (organisational role).

"[Chris]: We need the ability to share (large) files with external PR and design agencies.

[Richard]: Working with partners and customers is seriously inefficient; our competitors here in New York can collaborate online. I do a lot of sales bids and propositions and waste an extraordinary amount of time replicating and organising the work.

[Sylvia]: We would like to be able to give our media agency access to a sub workspace in the recruitment area. We receive a large number of zip files from them with graphics for the various campaigns we are running and quite often the zip files alone are over $50 \mathrm{MB}$ big. As you can imagine this blocks up our email accounts whenever it happens. Ideally, we would like them to be able to upload the files for us to review on this workspace.

[Alex]: We would like to exploit the features of the internal workspaces to help enhance the communications between us and the client on the Ofsted project. We would like to provide increased customer visibility of work-in-progress (KM group - Log of Change Request Forms, 2008).

The above suggestions came from actual interactions among Infoteka's consultants, customers and third parties. These suggestions were very sophisticated and based on various 'epistemic' backgrounds (represented by professional roles) and work contexts (represented by the organisational roles). This caused difficulties for the developers to refine and synthesise users' suggestions to arrive at final work structures. From the KM group's perspective, requests such as accessing a sub (external) workspaces, providing increased customer visibility of work-in-progress or providing full function of online collaboration were at odds with the viewpoints of IS professionals, who were concerned with the integrity of knowledge.

The second example is the request, whereby some consultants wanted to change the library hierarchy by expanding the content stores (i.e., containing project summaries, customer references, and sales and marketing) in the Our Knowledge environment. To illustrate, in the following feedback extracted from change request forms, Larson is a consultant of FS (professional roles) and a collateral manager (organisational roles) for the Swedish market; Jorgen and Caroline are both consultants of IDT (professional roles) and collateral managers (organisational roles) for the Swedish market; Lena is a consultant of public and healthcare (professional roles) and a collateral manager (organisational roles) for the Swedish market.

"[Larson]: We currently have troubles with the current library hierarchy. We suggest adding a new content store for financial services...Area ownership of this content store and the content store of IDT and public and healthcare should be assigned to our unit for easy uploading. We have more clients in this sector [FS] than any other sectors.

[Jorgen and Caroline]: We request to upgrade 2 content stores for EEU and IDT, or at least one for both. For more convenience in sharing and uploading, we also need area ownership. Area ownership for Larson's group may not be appropriate because we normally work with at least 10 third parties in North America, the Middle East and Australia, and we therefore need to regularly upload large files. This [authorisation from Larson's group] will be time consuming. [Lena]: We need to either have more functions control the area ownership for the public [sector] or integrate a small content store for healthcare into the existing library hierarchy. We are the only key player in this sector in this country, and thus we have projects from the government and some NGOs all year round. In either way, we need to be able to upload and share the document between the content stores easily (KM group - Log of Change Request Forms, 2007).

This feedback has revealed that among the requestors there was a conflict in terms of gaining area ownership as they all want to be able to directly upload and share the content between stores without waiting for authorisation. It was difficult for the KM group to mediate this conflict as all of them have good reasons in terms of their professional roles to apply for the ownership.

The third example is about the two sets of misalignment relating to the local management of workspace metadata and access permission. For this misalignment, the corporate administrators did not want the portal to provide local administrators with flexibility to define the local workspace metadata and access permission on their own. Thus, the corporate administrators' requests were at odds with what the system architects designed. Specifically, vendor's representatives argued that such requests would not work effectively because the local level should also be provided with 'similar' rights. The vendor's representative elaborated on the problem as follows:

"We understand their intention [managing workspaces at the corporate level only]. However, we do not think [that] this [request] would work. We have rich experience in dealing with this issue. I'll give you one example. A multinational [enterprise] customer with a branch in Shanghai (China) called our team some months ago, asking us to develop more functions to do [some] new works. . .This is a situation that they [business unit in Shanghai] did not expect. They said that some big guys in the head office could not understand 'urgent' needs and purposes of the local team to modify workspace metadata...So, back to your question, we tell him [the assistant to the KM manager], 'You may need to take this issue into account. We believe, sooner or later, it would happen. You should let them do the job at their level" (Green, vendor's representative, 29 Nov 2007).

We argue that the gap of social identities between the corporate and local level was the underlying factors that lead to misalignment. At the local level, in accordance with their professional identity assigned for daily work and projects, administrators also have their own judgments and rationale for doing locally specific knowledge works and particularly an insightful understanding of the environment surrounding their workplace. Such judgements, rationales, and understandings could be hardly caught by those even holding similar organisational roles (or professional roles) at the corporate level. Misalignment in this circumstance was a consequence of not taking a comprehensive view of professional identities as well as organisational roles of staff into account. Infoteka should have anticipated this misalignment in the preparation or pilot phase, not late after the system's roll-out.

\section{Discussion}

5.1. Reflections on misalignment of deliberately acquired institutional structures: implications for implementation

New institutional theory argues that an organisation can deliberately seek certain work structures, thereby gaining more 
legitimacy in its business environment. For this consultancy firm with its global operational context and large user base, there are two aspects to be considered. On the one hand, the strategic objectives ${ }^{19}$ set by management; e.g., 'A powerful global delivery capability' and 'A balanced market sector profile', prompted the need to strengthen expertise, experience, collaboration, and responses. Such objectives can be achieved by dynamically and effectively supporting KM processes (e.g., searching and grouping the results in content types, upgrading content stores, or enhancing reporting functions in the Our Knowledge and Workspace environment) by evolving selected organisational structures and routines. On the other hand, so many requests from this large diversified user community may cause confusion for the firm to decide and acquire the most appropriate structures since there are many implications of what are acceptable degrees ${ }^{20}$ of such requirements. We summarise the dimensions of imposed and deliberately acquired institutional structures with some typical examples in Table 1.

Regarding our research framework and the findings, although the number of misalignment instances due to mimetic and normative pressures is fairly low, we expect that throughout the implementation project these two institutional forces may exert more influences on KM software implementation. Since other competitors are well ahead of the case company in terms of KM implementation, ${ }^{21}$ this company still has many opportunities to benchmark itself against these leaders or peers by, for example, holding memberships in various KM professional associations both at corporate and local level or by buying best practices from information providers (e.g., Gartner).

Moreover, since the company's business context is characterised by uncertainty, ${ }^{22}$ becoming more internationalised ${ }^{23}$ and involving many industries, there is a need to acquire unique knowledge seeking and sharing structures. This is demonstrated by the requests by local managers for workspace metadata and accessibility changes; adding more functions into external workspaces to enhance collaboration and sharing; making business-specific topic pages; searching and grouping results in content type; or searching CVs/Skills in the My Information environment.

\subsection{Reflection on misalignments of imposed structured}

\subsubsection{Effects of institutional forces on the organisation's KM technology implementation project}

As far as the imposed structural misalignments are concerned, a thorough grasp of international and national rules and regulations,

\footnotetext{
19 This is specified in Infoteka's business strategy.

20 We observed that the final resolution for a misalignment is occasionally slightly different from what was initially requested. This was due to the outcome of the negotiation within the Change Control Board.

21 Among the world's top 10 IT-Management consultancy firms, there are up to six organisations that were nominated for MAKE (Most Admired Knowledge Enterprise) (Gartner, 2006). Inaugurated in 1998, the Most Admired Knowledge Enterprise (MAKE) Award was initiated by Teleos (a British foremost independent research company in knowledge management and intellectual capital areas) every year. It seeks to recognise organisations, which out-perform their peers in creating shareholder's wealth by transforming tacit and explicit enterprise knowledge and intellectual capital into superior products/services/solutions. It consists of the annual Global MAKE Award - the international benchmark for best practice knowledge organisations, and similar studies at regional/national levels. The winners of the Global MAKE Award are selected by an expert panel comprised of business executives from Fortune 500 companies, leading knowledge-management practitioners as well as intellectual capital experts (Hong Kong Most Admired Knowledge Enterprise, 2009).

22 As specified in Infoteka's corporate strategy and plan, many issues such as the political and physical supply pressure, changes of rules and regulations in the financial services, or new requirements for content in the telecom and media sector all contribute to the complexity and uncertainty of Infoteka's business environment.

${ }^{23}$ Also specified in Infoteka's corporate strategy and action plan.
}

together with industry standards and practices (e.g., via the firmsupplier and firm-customer relationships) has to be acquired for the KM technology implementation project to ultimately succeed. Equally important is understanding the work structures embedded in the software package. It is noteworthy that management and the KM team should be able to distinguish the unique context of their own organisation and that of the technology developers.

For example, understanding the industry type as well as the strategy and objectives of a KM initiative, and particularly pursuing questions such as 'What makes us different?' or 'What if?' may help clarify such contextual differences. Since this is a global organisation whose offices are based in over 30 countries, a wide variation of rules and regulations imposed by each country or industry may require significant effort and trade-offs. More specifically, the case company should be able to weigh the benefits obtained for the company itself and the concerned countries and industries, whilst maintaining its business and KM strategy.

\subsubsection{The nature of misalignment of imposed institutional structures}

In this study, we have identified and summarised the sources and types of misalignment of imposed structures (see Table 1). Still, what we are concerned with is the impact of institutional forces, both the coercive and normative, on the occurrence of potential misalignments throughout the KM software lifecycle. Underpinned by Majchrzak's et al. (2000) viewpoints on the causes of changes in structures of technology (and in virtual teams), we contend that over time more and more routines and structures may continually arise as a result of the frequent interactions of this global firm, which also involves a large user base, with the government and industry (including partners, suppliers and clients) of each country. These structures and routines may eventually give rise to even more complex conflicts that are worth considering. In this regard, what is worth mentioning in this case is the KM group's attitude towards the changing of structures.

"We could receive new requests for change in the future as our business's nature is pretty much uncertain. This may be because of customers' requirements or changes of business environment. . This year our staff in Dubai reported a problem of sharing content within the workspaces to the [KM] group. . Next year, we may have similar problems in South America or the Philippines...Pavel [KM programme manager] and I see the [change] requests as opportunities for [a] better performance, for clients. . and therefore we'll try to embed [such requested] practices into our [as-usual] business processes"(Zaynes, IT professional and KM coordinator in USA, 25 Sept 2008).

For further illustration, we provide some opinions of staff members extracted from the company's documents (Infoteka - Issue logs of KM group, 2008; Infoteka - Issue logs of service team, 2008). Josh is a consultant in the E\&U sector in Dubai (UAE); Lana is a consultant in T\&M sector in the Philippines; Cristiano is a senior consultant in the IDT sector in San Paolo (Brazil).

[Josh]: Our team expects that next year our clients may require additional changes in accessing the external workspaces. For example, we may have to add more functions. Pavel [the KM programme manager], could you keep this issue in your agenda please? We need to prepare from now.

[Lana]: I am not sure if we do not have to change. But we should think if we could be able to customise our sales channel in the workspaces for our key clients. This sale channel should be made 'visible' so that clients can see the progress. This is one of important requirement in the TEM this year.

[Cristiano]: Hi Pavel, can we create a function to allow our customers to share technical knowledge? I guess we may have conflict 
Table 1

A summary of imposed and deliberately acquired institutional structures.

\begin{tabular}{|c|c|c|c|}
\hline Structure and its dimensions & Descriptions & Examples & \\
\hline \multirow{2}{*}{$\begin{array}{l}\text { Imposed institutional } \\
\text { structures }\end{array}$} & Countries & Governmental policies & Government policies of privacy and data protection \\
\hline & Industry differences & $\begin{array}{l}\text { Inter-relationship of firm-supplier and } \\
\text { firm-customer }\end{array}$ & Pressure for new content innovation in the T\&M industry. \\
\hline \multirow[t]{5}{*}{$\begin{array}{l}\text { Deliberately acquired } \\
\text { institutional structures }\end{array}$} & $\begin{array}{l}\text { Adapting to strategic } \\
\text { contingencies }\end{array}$ & $\begin{array}{l}\text { - Reflecting the complexity of } \\
\text { environmental components into the } \\
\text { company's knowledge work structures }\end{array}$ & $\begin{array}{l}\text { - Upgrading the library hierarchy to expand the content } \\
\text { stores of the Our Knowledge environment }\end{array}$ \\
\hline & & - Satisfying management and users' & - Upgrading the reporting functions within the Our \\
\hline & & interests & $\begin{array}{l}\text { Knowledge environment } \\
\text { - Local management of workspaces' metadata and } \\
\text { permission for access }\end{array}$ \\
\hline & & & - Searching and grouping results in content types \\
\hline & Industry and profession & Learning from peers & Searching CV/Skills within My Information environment \\
\hline
\end{tabular}

with customers in the Middle-East, but this can help improve our performance here.

Since knowledge, information, and data are the central objectives of the computing industry, which has been evolving tremendously, and given the ever-changing social, economic, and political context nowadays, we believe that the institutional context will further influence KM technology implementation. There is then a need for more studies to look into how and in what aspects the institutional context can affect KM technology developers and adopters.

\subsection{Institutional effects on acquiring and evolving emergent knowledge work practices}

Getting a consensus on acquiring and evolving emergent work practices is even more challenging given that our research setting is a global knowledge-intensive firm. Indeed, Robertson et al. (2003) suggest that the current trend of employing multidisciplinary teams for knowledge creation tasks may be problematic. Specifically, if such teams span professional domains that have fundamentally differing epistemological bases, ${ }^{24}$ and, thus, differing epistemic cultures, then even converging opinions of how to acknowledge and develop new knowledge work practices may be problematic. Given our research setting, we therefore argue that acknowledging appropriate knowledge work practices and embedding them into KM software packages could be challenging. This case company's approach to projects is to assign staff from a common staff pool to work in different service sectors. One may work within a project of the E\&U sector and the next time work with a project in the S\&D sector. In so doing, the company believes that its expertise and experience can be effectively diffused across the service sectors, thereby achieving a balanced market sector profile. This approach, however, is difficult in terms of identifying and embedding (or changing) appropriate knowledge work practices into the technology because a particular team doing projects actually consist of members holding differing epistemological backgrounds. In a context having diverse user groups or communities of practice, with different work practices and differing epistemic cultures, and with different levels of background experience, Wagner and Newell (2004) argue that the market trend of embedding a single industry solution into a software package may not secure an implementation success from all the relevant perspectives, because the developers mandate one epistemological position through their software design. This could be a limitation of KM technology in this case company.

\footnotetext{
24 For more details, please refer to our review of special features of institutional context in professional service firms in Section 2.4.
}

Robertson et al. (2003) contend that in professional service firms a strong social identity can be revealed via exceptional working facilities and resources made available. In line with their opinion, in this case company, we also found that the generously expensive firm-wide KM events that took place, ${ }^{25}$ the position of this company in the worldwide marketplace, and the calibre of the client base ${ }^{26}$ served to promote a strong professional identity. From an institutional theory perspective, we therefore believe a strong professional identity could be a motive for consultants to identify emergent work structures, thereby prompting the need for embedding them into the technology. So long as an awareness of both professional identity as well as organisational role of staff is not fully taken into account, the probability of encountering similar or new misalignments may be high. Alternatively, underpinned by Robertson's et al. demonstration that people define their social identities through the knowledge they generate, we argue that, by requesting to embed certain knowledge work practices into a KM software package, the consultants did take steps to strengthen their social identities across the multiple communities of practice of this case company. This claim is demonstrated by the examples mentioned in Section 4.2.3.

\subsection{Reflection on the application of institutional theory}

For this study, employing institutionalism was useful for analysing data collected from the field. Specifically, this theory provided us with an awareness of institutional pressures such as coercive and normative, and particularly the vocabulary to understand why and how our case organisation was imposed upon by the nation state authorities and industry control groups to gain legitimacy in its business environment. Furthermore, the institutionalism was also important to interpret and elaborate on why and how our case organisation pro-actively responded to changes in its business or operational environment. Put simply, this theory assisted us to gain insights into why and how our case organisation went through the change process of its knowledge work practices under the influences of the governments, industries and business context.

Neo-institutionalism has been widely adopted in a number of studies to investigate IT/IS related phenomena such as IT innovation, IT development and implementation, and IT adoption and use (Ali-Hassan, 2005; Currie, 2009; Mignerat \& Rivard, 2009). Notably,

\footnotetext{
25 This case company dedicated significant organisational resources into the KM programme by holding a series of conferences, seminars and events in the countries where it operates throughout the year. All those events aim at promoting the deployment of KM activities. During our eleven-month field work, we observed that Infoteka organised 1 corporate event and 4 seminars on KM in 5 countries.

26 Please refer to Section 4.1 for more details about Infoteka's customer track record.
} 
within the IS literature, among the existing research paradigms, the positivist approach has been employed much more than the interpretive approach. This, as argued by Weerakkody, Dwivedi, and Irani (2009, p. 365), suggests that scholars are neglecting richer paradigms (i.e., interpretive) that have implications for editors, reviewers and authors'. This study therefore hopes to contribute to this aspect of the IS literature.

The adoption and implementation of KM software has gained momentum worldwide. However, so far, as far as we have reviewed, there are only three studies that look into KM software implementation from an institutional theory perspective. Research conducted by Purvis, Sambamurthy, and Zmud (2001) is perhaps the first that looks into the adoption of a knowledge platform in organisational contexts. Specifically Purvis et al. examine features that support effective project management, such as how existing rules, regulations, and norms negatively affect the use of this knowledge platform. However, the limitation of their study is that they do not give rich insights into the adoption and implementation process; e.g., how staff members, groups or departments react to requirements for change. Our study makes a contribution in this regard.

Another research is that of Butler (2003) looking at the use of intranet-based information systems. His study, however, does not focus directly on the impact of institutional pressures. Rather, it examines the organisational commitments to the development and implementation of such intranet-based information systems. In our study, we understand how authoritative control through norms and values is implicated in the characteristics of use of a KM software package. Recently, Rizzi, Ponte, and Bonifacio (2009) investigate the managers' decision to invest into KM technologies under institutional pressures. Like the study of Butler (2003), their research therefore does not explicitly address the influences of institutional forces on the KM technologies.

The industry of this case company is an IT-management consulting, and so this case company is not in a highly regulated domain. There are understandably not many findings relating to coercive and normative pressures. However, we argue that the existence of such institutional forces in this case may not be as clearly evident as in the case of ERP system implementation (see for example, Sia \& Soh, 2007; Soh \& Sia, 2004). This is because we found that the majority of governmental rules and regulations or industry norms just focus on some limited aspects of knowledge work processes, such as knowledge creation, sharing, and archiving. We suspect this fact may be the case since the rules and regulations have not caught up with the technology and how it may be used, changed, and developed in practice. This finding, therefore, implies that coercive and normative pressures may not exert the same level of influences on a KM technology implementation as on an ERP system implementation.

\subsection{Implications for institutional theory and organisations}

Interestingly, this study, to some extent, demonstrates Chattterjee, Grewal, and Sambamurthy's (2002; see also Mignerat \& Rivard, 2009) argument that in addition to the organisation itself, which has been widely considered as 'an institution' in the literature, senior management (here represented by the roles of KM programme manager, KM roll-out project managers, and content managers) are indeed 'institutions' because, as defined by Scott (1995), they are a 'social structure' (i.e., roles within organisations) giving the organisation roles within the organisation lines of actions or orientations, whilst controlling and constraining them. Further, our analysis also shows that senior management did follow an institutionalisation process whereby they, under the influence of institutional forces, decide either to adapt organisational practices to the practices embedded within the portal or customise the portal to fit the existing organisational practices. For IT adoption and innovation, a need for broader definitions of institutions is important towards analysing the effects of institutional forces (Mignerat \& Rivard, 2009).

\subsection{KM system and its characteristics: goal-oriented and identity-creating}

This study adds to the richness of the literature on knowledge management, and, in particular, supports a view of the organisation as a system of practice, whereby practice is meant as both goal-oriented and identity-creating (Spender, 1995, 1996, 2006). Indeed, in analysing and discussing the misalignment phenomenon throughout the KM technology implementation project, this study presents an insight into the 'practice' dimension of the KM system by laying stress on two characteristics - goal-oriented and identity-creating. ${ }^{27}$ These characteristics by nature tie into the resource-based perspective, in which theorists suggest that organisations evolve distinct routines and structures (and the resultant practices) for acquiring and managing their strategic resources (Eisenhardt \& Martin, 2000; Porter, 1996; Soh \& Sia, 2004; Teece, Pisano, \& Shuen, 1997).

In discussing the process in which consultants identified existing and emergent knowledge work practices and then got them either changed within or embedded into the technology (or their company), this study demonstrates the interplay between KM technology, people, and KM processes. This kind of interaction is also central to Spender's (2006) notion of a complex system. In particular such interplays reveal the dynamics of practice conducted by the system and the diversity of meanings offered by the system. Whilst the dynamics of practice has been reflected in our analysis (e.g., during the process of identifying and acknowledging emergent knowledge work practices), we believe this diversity of meaning exists in a sense that the system itself offers various knowledge work contexts that eventually result in differing ways of interpreting 'misalignment' ${ }^{28}$ or 'how to perform a specific knowledge work practice'.

\subsection{Special features of KM to be incorporated into the KM technology: implications}

By exploring KM software-organisations misalignments, we were interested in seeing what special features of KM are incorporated into KM technology and how this is done. Indeed, many instances of misalignments have exposed some special features of KM being incorporated into the software package. Specifically, the extent to which KM processes are 'embedded' in the KM software appears to be more dependent on factors such as the knowledge types $^{29}$ (Tiwana, 2000) and speed, efficiency and accessibility. ${ }^{30}$ This can be exemplified by examples such as the embedding (or changing) of emergent work structures for (i) locating and connecting experts across the firm based on skills described in the $M y$

\footnotetext{
27 With regards to 'goal-oriented' characteristic, a typical example is the misalignment relating to searching and grouping in content types. By accepting the requests, the KM group attempted to resolve the inefficiency in extracting content. Regarding 'identity-creating' characteristic, typical examples include misalignments arising from coercive and normative pressures (see Table 1). In resolving such misalignments, the case company not only gained legitimacy but also created and maintained its identity in the global consulting industry.

${ }^{28}$ For example, the misalignment theme relating to local management of workspace metadata and access shows that there are various ways to manage and control workspaces from either the corporate or the local point of view.

${ }^{29}$ Differences in knowledge types (i.e. text, graphic, audio or video) will result in differences in how individuals create, share (upload and download) and store the contents.

30 Speed, efficiency and accessibility are three important factors for KM technology from a knowledge based perspective. See Section 2.2.
} 
Information environment (e.g., to improve efficiency); (ii) searching for and grouping by content type (e.g., to improve speed and efficiency); (iii) upgrading the library hierarchy to assist in uploading and sharing of content after company acquisition (e.g., to improve efficiency and accessibility); and (iv) upgrading more functions into the external workspaces to assist consultants to work on different types of content (i.e., graphic, video or audio).

Interestingly, as shown in our analysis, the process of managing knowledge in a KM software package could be more complex and malleable as the nature of knowledge (i.e., know-how and knowwhat) is very volatile, and, especially, new knowledge is always interpreted or understood in the context of existing knowledge (Boudreau \& Robey, 1996, 1999). Even when the knowledge is not outdated, the knowledge workers may question the interpretation of the content given changes in the external business environment (Malhotra, 2005). This is reflected in our case where, in the request for searching and grouping results by content types, the KM rollout project manager and senior consultants talked about the need for a navigation function to guide users towards the right place to increase search relevance; or the request to upgrade the reporting functions within the Our Knowledge/Workspace environments; or the request to make business specific topic pages. For better control of KM processes and structures, it may be helpful if implementing organisations intentionally look for a technology product that has sufficient 'room' or acquire license codes from KM vendors or developers for their own 'deep' configuration.

\section{Conclusions}

\subsection{Theoretical contributions}

IS implementation often aims at triggering changes in work practices and in organisational structures such as policies and procedures (Vaast \& Walsham, 2005). In other words, IS are deeply implicated in changes that are occurring by offering their power to enable emergent ways of working, collaborating, and managing across space and time (Walsham, 2002). The IS literature has documented changes in practices that emerge with IT use as well as how these changes are related to organisational transformation (see e.g., Barrett \& Walsham, 1999; Newell, Scarbrough, \& Swan, 2001; Orlikowski, 1996; Schein, 1978; Schultze \& Boland, 2000; Schultze \& Orlikowski, 2004; Sia \& Soh, 2007). One related issue, however, remains under-explored: What factors prompt organisational staff to be aware of such changes in practice? In other words, there has been an ignorance of the root of differences in practices that subsequently result in the need for organisational transformation. This is particularly true of the knowledge management area. Although studies by Orlikowski (1996), Schultze and Boland (2000), and Majchrzak et al. (2000) have conceptualised the link between practice change and organisational change from the structurational and situated practice perspectives, they have not shown sufficient insights into the sources of such requirements for changes. This study has therefore attempted to enrich this understanding.

This study employs institutional theory. Although neoinstitutionalism has been used to examine IT/IS in organisations for over twenty years, there is an emerging set of studies, which focuses on the interaction between IT and institutions; including the studies of Soh and Sia (2004), Sia and Soh (2007), Currie and Guah (2007) (see e.g., Mignerat \& Rivard, 2009; Weerakkody et al., 2009). This study also aims to contribute to this stream of literature.

Moreover, findings of this research could help enhance our understanding of misalignment between IS and organisational requirements. Specifically, as shown in our analysis, the majority of misalignment instances were due to developmental/contextual modification requirements, rather than system flaws or failures. Our claim supplements previous studies of Soh and Sia (2004) and
Sia and Soh (2007). The key difference between our study and theirs is that their findings seem to emphasise system flaws or failures as opposed to developmental/contextual modification requirements. The reason lies in the difference between an ERP system and a KM system. For an ERP system (or alternatively, accounting software), the ultimate objective is data and information while for a KM system, the ultimate target is knowledge. Once the work context is changed, the content (know-how and know-what) may also be automatically changed to fit the newly-emerging context for re-use (better references), and hence this could result in changing existing (or creating new), for instance, searching practices to find and extract the relevant items.

That the majority of misalignment instances were due to developmental/contextual modification requirements, rather than system flaws or failures also prompts us to reflect on the businessIT alignment research. Indeed, in line with Chan and Reich's (2007) reflections, our findings echo criticism that any IT-business alignment model is problematic as the business strategy and context can be changed any time and also because achieving stability upon aligning IT with business is not always feasible since the knowledge work context could be changed throughout the technology implementation to fit the emergent context. More importantly, thanks to identifying and tackling misalignments, our findings support Carr's (2003) account that an organisation might be able to make IS use and performance somewhat more unique thereby enhancing its competitive advantage in the market place.

Notably, this research could be seen as a response to the call made by Orlikowski and Barley (2001, p. 158), "In particular, we advocate for research that requires substantive expertise in both technology and the social dynamics of organising and that embraces the importance of simultaneously understanding the role of human agency as embedded in institutional contexts as well as the constraints and affordances of technologies as material systems". Moreover, this call indicates the need for research that focuses on different levels of analysis as well as research that adopts a process-oriented perspective (Pettigrew, Woodman, \& Cameron, 2001), exploring enterprise systems design, development, and use over time. By demonstrating the social dynamics and particularly the role of human agency both at the group (CoPs)/departments and individual levels in identifying the existing and emergent knowledge work structures and then either getting them changed within or getting them embedded into KM technology (or the case organisation), our research could help add value to such an important aspect of the IS literature, in general, and the literature on KM technology, in particular.

Specifically, viewed from the lens of institutional theory, our study may arguably be the first of its kind to demonstrate how institutional forces exert influences on KM technology adoption and implementation in an actual business case, thereby enriching institutional theory. In our study, we understand how authoritative control through norms and values is implicated in the characteristics of use of KM software package. We believe this contribution may potentially enhance our understanding of an under-developed area of IS research: misalignment of knowledge work structures caused by institutional pressures, especially in the context of a multinational adopting environment. For example, our case organisation, a global consultancy firm, is a good illustration of country-level and industry-level differences in terms of KM technology adoption. Understanding the impact of institutional forces on KM technology implementation is an indispensable part of IS research, such as IS design, innovation, development and use as Meyer and Rowan (1977, p. 352) emphasizes, organisations that devise structures to conform closely to institutional requirements 'maximise their legitimacy and increase their resources and survival capabilities'.

Together with research available in the IS literature (see e.g., Barrett \& Walsham, 1999; Currie, 2009; King et al., 1994; Kling \& 
Iacono, 1989; Sia \& Soh, 2007; Soh \& Sia, 2004), this study should be seen as another effort to address the issue of how institutions influence the design, use, and consequences of technologies, either within or across organisations. From an organisation science perspective, by including insights from institutional theory, we have developed a more structural and systemic understanding for how (KM) technologies are embedded in complex interdependent social, economic, and political networks, and how they are consequently shaped by such broader institutional influences (Orlikowski \& Barley, 2001). Given increasing technological dependence within organisations, exploring such issues is highly salient as they "profoundly affect the manner, quality, and outcomes of organisational realities" (Orlikowski \& Scott, 2008, p. 5).

This study, together with the empirical research of Soh, Kien, and Tay-Yap (2000), Soh et al. (2003), Soh and Sia (2004), and Sia and Soh (2007), could help strengthen Walsham's (2001) argument that global diversity needs to be a primary concern when designing, developing and using enterprise systems. Although these authors acknowledge Walsham's account with regards to empirical evidence found in their own research setting of ERP systems implementation, there is virtually no study in the context of KM technologies implementation. This acknowledgement is particularly significant in that $\mathrm{KM}$ and its technologies are of cultural and global issues (see e.g., Cummings, 2004; McDermott, 2000; Okunoye \& Bertaux, 2006; Zakaria, Amelinckx, \& David, 2004; see also Walsham, 2008). The issue of KM technology implementation together with the research setting - a global consultancy firm whose offices are located in over 35 countries - therefore fit into this 'gap' of the IS literature.

By providing insights into changes or emerging knowledge work practices, this study could be a contribution to the literature on critical success factors (CSF) for KM. More specifically findings of this study are consistent with the IT/IS project management literature, which advocates organisational and behavioural change management as critical success factors in the implementation of information systems (Alavi \& Joachimsthaler, 1992). For example, how senior managers control different types of change of work practice, particularly emergent and opportunities-based changes, or the plans and strategies to deal with different types of misalignment could prompt researchers to investigate issues of how to be better prepared for misalignment problems or to minimise the incurred loss of investment. Moreover, although our reading of the KM literature has identified many factors that are critical for a successful implementation of KM initiatives in general, we have not found studies that deliberately address CSF for KM technology implementation, except for the study by Remus (2007). This study thus could helpfully pave the way towards discovering CSF for implementing KM technology projects.

\subsection{Practical contributions: some lessons learned for practitioners}

This study has demonstrated the effects of institutional pressures and features on identifying and embedding knowledge work structures in organisations, and hence, provided some valuable lessons learned for organisations that either plan to adopt or currently implement KM systems.

First of all, it is important that adopting organisations review their strategic objectives. An analysis of both what and how they wish to do with their business will give them some insight as to what aspects of their KM initiative needs to be improved. In other words, they will know how they can employ KM systems to support which kind of KM processes, thereby ultimately enriching content and strengthening networking, collaboration, and responses. Besides, organisations need to systematically review international and national rules and regulations together with industry's standards and practices (e.g., via the firm-supplier and firmcustomer relationships) prior to deploying and implementing the KM system. Such consideration would help to ensure that adopting organisations, especially international ones, are dynamically responsive to requirements because of the pursuit of legitimacy worldwide. Although findings in this research have shown that at times, rules and regulations may not catch up with what the software can be used for and how it is subsequently modified and developed, we anticipate that this gap could be narrowed down soon.

Second, from a knowledge-focused perspective, technology developers commodify knowledge and present 'packaged' solutions in complex information systems, which create problems for prospective users who need to unpack this knowledge and integrate it into existing organisational knowledge (Newell, Swan, \& Galliers, 2000). In uncovering the sources of misalignment, our study could be a practical reference for those organisations that plan or attempt to acquire software packages for their KM initiatives to see how such knowledge should be 'unpacked' and then integrated into organisational knowledge bases in an actual implementation process. For example, solving misalignment relating to searching and grouping in content types requires us to understand the differences in epistemological bases between those that were assumed and inscribed into the KM technology and those that are adopted by the case organisation. Even more important is the need to converge various individual opinions of how to acknowledge and develop new knowledge work practices. This lesson is very significant given the speed of KM technology adoption worldwide.

Another lesson that emerges from our study is that a strong professional identity can help in acting as a catalyst for staff to identify emergent knowledge work structures, which will then be embedded into the system. Additionally, by identifying such emergent work structures, staff may also have a good chance to strengthen and reinforce their professional identities across their organisations. This may pose problems and challenges not only for managers tasked with the delivery and implementation of the system but also for senior managers charged with the operation of the organisation itself. Further, in providing insight into the impacts of institutional features such as epistemological bases and professional identities, our research implies that not only adopters but also software developers and designers should pay serious attention to such institutional features earlier in their design and adoption phases.

Fourth, unlike other enterprise systems such as ERPs or CRMs, unpacking the knowledge inscribed into KM software is more challenging as different organisations hold different views of KM processes, practices, and assumptions (i.e., knowledge sharing culture, relationships between KM styles and industry types (Choi \& Lee, 2003)), and this therefore leads to a variety of package configurations. There is a lack of a dominant design in this respect (Abernathy \& Utterback, 1978). Informal discussions with the KM group and two vendor's representatives highlight that the adopting organisation should play a pro-active role in raising the KM technology developers' awareness of the institutional context, including industry types and knowledge types (see e.g., Choi \& Lee, 2003; Tiwana, 2000) that may give rise to different work structures and routines over time. Firms may hold seminars and workshops or join professional associations to promote their awareness of the institutional context and to have in-depth discussion about the industry where the firm is and about which type of knowledge is appropriate or needed.

Lastly, our research offers an important implication for practitioners. We believe that misalignments could still arise throughout the KM software lifecycle. This may be attributable to Teo and Men's (2008, p. 558) claim that "The major difference between knowledge portals and traditional IS lies in uncertainty". The impact of institutional environment on the KM technology implementation project in this case company somewhat exemplified this 
uncertainty. Among many existing factors, understanding this lesson is decisive for both KM project management success and system design and development.

\subsection{Limitations and recommendation for future research}

Results of this study must be interpreted in the context of its limitation. First, institutions and their effects can be studied at different levels of analysis, and the level for analysis in this paper is just the department/business units and individuals implementing KM technology. Second, given Markus and Tannis's (2000) fourphase enterprise system lifecycle and the actual implementation, this single case study has only encountered the first three phases. ${ }^{31}$ Misalignments arising during the fourth phase, which continues from normal operation until the system is replaced by an upgrade or a different system, remain unexplored. This latter phase is essential for a complete assessment of the misalignments between the portal and this global firm.

In this study, it was our intention to incorporate the technology side into the conceptual framework. There has been, however, a somewhat light focus on the KM technology vendor side. Despite attempts, gaining full access to the vendor firm was ultimately challenging. Nonetheless, formal contact with two representatives from the vendor was made and developed during the fieldwork in this case organisation. This yielded a number of small yet richly focused discussions that explored the perception of misalignment from the vendor's point of view. However, while these formal interviews were insightful for this study, it remains a frustrating potential bias that the field research and analysis could not give equal attention to both the vendor firm and the case organisation. Lastly, given the dearth of technology vendors' reflections on softwareorganisations misalignment in the IS literature, ${ }^{32}$ we believe that taking and maintaining their view could somewhat add value to this conceptual framework.

Future research should look into misalignments identified from a more highly regulated domain such as legal or health-care services or how such misalignments influence the way management decides to response via organisational adaptation or KM software customisation. Examining what actually happened during the last phase (of the four phases mentioned by Markus and Tannis) could also produce some interesting results.

\section{References}

Abbott, A. (1988). The system of professions. London: University of Chicago Press. Abernathy, W. J., \& Utterback, J. M. (1978). Patterns of industrial restructuring. Technology Review, 80(7), 1-9.

Akhavan, P., \& Jafari, M. (2006). Critical issues for knowledge management implementation at a national level. Journal of Information and Knowledge Management Systems, 36(1), 52-66.

\footnotetext{
31 At the time when we left the field work.

32 For example, studies by Orlikowski (1996), Majchrzak et al. (2000), Schultze and Boland (2000), Soh et al. (2000), Soh and Sia (2004) and Sia and Soh (2007) did not explicitly consider vendors' perspectives on misalignments and even focused entirely on the adopting organisation side.
}

Alavi, M., \& Joachimsthaler, E. (1992). Revisiting DSS implementation research: A meta-analysis of the literature and suggestions for researchers. MIS Quarterly, 16(1), 95-116.

Ali-Hassan, H. (2005). Theories used in is research: Institutional theory. Available at: http://www.istheory.yorku.ca/institutionaltheory.htm Accessed 06.03.07

Alvesson, M. (1993). Organizations as rhetoric: Knowledge-intensive firms and the struggle with ambiguity. Journal of Management Studies, 30(6), 997-1015.

Alvesson, M. (2000). Social identity and the problem of loyalty in knowledgeintensive companies. Journal of Management Studies, 37(8), 1101-1123.

Ashforth, B., \& Saks, A. (1995). Work-role transitions: A longitudinal examination of the Nicholson model. Journal of Occupational and Organizational Psychology, 68, $157-175$.

Asian Knowledge Management Association. (2007). The Business Management Certification program. Available at: http://www.akma.com.hk/ Accessed 04.04.07

Barrett, M., \& Walsham, G. (1999). Electronic trading and work transformation in the London insurance market. Information Systems Research, 10(1), 1-22.

Besson, P., \& Rowe, F. (2001). ERP project dynamics and enacted dialogue: Perceived understanding, perceived leeway, and the nature of task-related conflicts. ACM SIGMIS Database: Special Issue on Critical Analyses of ERP Systems: The Macro Level, 32(4), 47-66.

Boudreau, M. C., \& Robey, D. (1996). Coping with contradictions in business process re-engineering. Information Technology and People, 9(4), 40-57.

Boudreau, M. C., \& Robey, D. (1999). Accounting for the contradictory organizational consequences of information technology: Theoretical directions and methodological implications. Information Systems Research, 10(2), 167-185.

Burt, R. S. (1982). Toward a structural theory of action: Network models of social structure, perception, and action. New York, NY: Academic Press.

Butler, T. (2003). An institutional perspective on developing and implementing intranet- and internet-based information systems. Information Systems Journal, 13(3), 209-231

Carr, N. G. (2003, May). IT doesn't matter. Harvard Business Review, 41-49, http://www.scribd.com/doc/14468461/Carr-03-IT-Doesnt-Matter.

Chan, Y. E., \& Reich, B. H. (2007). IT alignment: What have we learned? Journal of Information Technology, 22, 297-315.

Chattterjee, O. D., Grewal, R., \& Sambamurthy, V.(2002). Shaping up for e-commerce: Institutional enablers of the organizational assimilation of web technologies. MIS Quarterly, 26(2), 65-89.

Choi, B., \& Lee, H. (2003). An empirical investigation of KM styles and their effect on corporate performance. Journal Information E' Management, 40, 403-417.

Computer Weekly. (2003). Knowledge management failures central to Shuttle disaster. Available at: http://www.computerweekly.com/Articles/2003/08/27/ 196769/report-knowledge-management-failures-central-to-shuttle.htm Accessed 23.03.07

Covaleski, M. A., \& Dirsmith, M. W. (1988). An institutional perspective on the rise, social transformation, and fall of a university budget category. Administrative Science Quarterly, 33(4), 562-587.

Cummings, J. N. (2004). Work groups, structural diversity, and knowledge sharing in a global organization. Management Science, 50(3), 352-364.

Currie, W. L. (2009). Contextualising the IT artefact: Towards a wider research agenda for IS using institutional theory. Information Technology \& People, 22(1), 63-77.

Currie, G., \& Suhomlinova, O. (2006). The impact of institutional forces upon knowledge sharing in the UK NHS: The triumph of professional power and the inconsistency of policy. Public Administration, 84(1), 1-30.

Currie, W. L., \& Guah, M. W. (2007). Conflicting institutional logics: A national programme for IT in the organisational field of healthcare. Journal of Information Technology, 22, 235-247.

DeCarolis, D. M., \& Deeds, D. L. (1999). The impact of stocks and flows of organizational knowledge on firm performance: An empirical investigation of the biotechnology industry. Strategic Management Journal, 20(10), 953-968.

DeSanctis, G., \& Poole, M. S. (1994). Capturing the complexity in advanced technology use: Adaptive structuration theory. Organisation Science, 5(2), 121-147.

DiMaggio, P. J. (1988). Interest and agency in institutional theory. In L. G. Zucker (Ed.), Institutional patterns and organizations: Culture and environment. Cambridge, MA: Ballinger.

DiMaggio, P. J., \& Powell, W. W. (1983). The iron cage revisited: Institutional isomorphism and collective rationality in organisational fields. American Sociological Review, 48(2), 147-160.

Drazin, R. (1990). Professionals and innovation: Structural-functional versus radical structural perspectives. Journal of Management Studies, 27(3), 245-263.

Dyer, J. H., \& Nobeoka, K. (2000). Creating and managing a high-performance knowledge-sharing network: The Toyota case. Strategic Management Journal, 21, 345-367.

Eisenhardt, K. M., \& Martin, J. A. (2000). Dynamic capabilities: What are they? Strategic Management Journal, 21(10-11), 1105-1121.

Ezingeard, J.-N., Leigh, S., \& Chandler-Wilde, R. (2000). Knowledge management at Ernst \& Young UK: Getting value through knowledge flows. In Proceedings of the 21st international conference on information systems (pp. 807-822).

Farjoun, M. (2002). The dialectics of institutional development in emerging and turbulent fields: The history of pricing conventions in the online database industry. Academy of Management Journal, 45, 848-874.

Gosain, S. (2004). Enterprise information systems as objects and carriers of institutional forces: The new iron cage. Journal of the Association for Information Systems, 5(4), 151-182

Grant, M. (1996). Toward a knowledge-based theory of the firm. Strategic Management Journal, 17, 109-122. 
Halliday, T. (1985). Knowledge mandates: Collective influence by scientific, normative and syncretic professions. British Journal of Sociology, 36(3), 421-439.

Hoffman, T. (2002). Knowledge management pays off for BAE systems. Available at: http://www.computerworld.com/databasetopics/data/story/0,10801,75022,00. html Accessed 04.04.07

King, J. L., Gurbaxani, V., Kraemer, K. K., McFarlan, W. F., Raman, K. S., \& Yap, C. S. (1994). Institutional factors in information technology innovation. Information Systems Research, 5(2), 139-169.

Klein, H. K., \& Myers, M. D. (1999). A set of principles for conducting and evaluating interpretive field studies in information systems. MIS Quarterly, 23(1), $67-93$

Kling, R., \& Iacono, S. (1989). The institutional character of computerized information systems. Office: Technology and People, 5(1), 7-28

Knorr-Cetina, K. D. (1999). Epistemic cultures: How the sciences make knowledge. Cambridge, MA: Harvard University Press.

Kogut, B., \& Zander, U. (1996). What firms do? Coordination, identity and learning. Organisation Science, 7, 502-518.

Kontzer, T. (2003). Knowledge management has gone from pie-in-the-sky promises to more realistic applications. Information Week.. Available at: http:// www.informationweek.com/story/showArticle.jhtml?articleID $=13100330$ Accessed 23.03.07

Latour, B. (1992). Where are the missing masses? The sociology of a few mundane artefacts. In W. E. Bijker, \& J. Law (Eds.), Shaping technology building society (pp. 225-258). Cambridge, MA: MIT Press.

Macdonald, K. (1995). The sociology of the profession. London: Sage Publication.

Maier, R., \& Remus, U. (2001). Towards a framework for knowledge management strategies: Process orientation as strategic starting point. In Proceedings of the 34th Hawaii international conference on system sciences (pp. 34-43).

Majchrzak, A., Rice, R. E., Malhotra, A., King, N., \& Ba, S. (2000). Technology adaptation: The case of a computer-supported inter-organisational virtual team. MIS Quarterly, 24(4), 569-600.

Malhotra, Y. (2004). Why knowledge management systems fail? Enablers and constraints of knowledge management in human enterprises. In E. D. Michael, T. Koenig, \& T. Kanti Srikantaiah (Eds.), Knowledge management lessons learned: What works and what doesn't (pp. 87-112). Information Today Inc. (American Society for Information Science and Technology Monograph Series)

Malhotra, Y. (2005). Integrating KM technologies in organizational business processes: Getting real time enterprises to deliver real business performance. Journal of Knowledge Management, 9(1), 7-28.

Markus, M. L., \& Tanis, C. (2000). The enterprise systems experience-from adoption to success. In R. W. Zmud (Ed.), Framing the Domains of I.T. Research: Glimpsing the Future (pp. 173-207). Pinaflex: Cincinati.

Massey, A. P., Montoya-Weiss, M. M., \& O’Driscoll, T. M. (2002). Knowledge management in pursuit of performance: Insights from Nortel Networks. MIS Quarterly, 26(3), 269-289.

McDermott, R. (2000). Why information technology inspired but cannot deliver knowledge management? In E. L. Lesser, M. A. Fontaine, \& J. A. Slusher (Eds.), Knowledge and Communities (pp. 21-36). London: Butterworth-Heinemann.

Meyer, J. W. (1994). Rationalized environments. In W. R. Scott, \& J. W. Meyer (Eds.) Institutional environments and organizations: Structural complexity and individualism (pp. 28-54). London: Sage Publications.

Meyer, J. W., \& Rowan, B. (1977). Institutionalized organizations: Formal structure as myth and ceremony. American Journal of Sociology, 83, 340-363.

Miles, M. B., \& Huberman, A. M. (1994). Qualitative data analysis: An expanded sourcebook. Thousand Oaks, California: Incorporated Sage Publications.

Mignerat, M., \& Rivard, S. (2009). Positioning the institutional perspective in information systems research. Journal of Information Technology, 24, 369-391.

Newell, S., Scarbrough, H., \& Swan, J. (2001). From global knowledge management to internal electronic fences: Contradictory outcomes of intranet. British Journal of Management, 12(2), 97-111.

Newell, S., Swan, J. A., \& Galliers, R. D. (2000). A knowledge-focused perspective on the diffusion and adoption of complex information technologies: The BPR example. Information Systems Journal, 10(3), 239-259.

Nicolaou, A. I. (1999). Social control in information systems development. Information Technology \& People, 12(2), 130-147.

Nonaka, I., Toyama, R., \& Nagata, A. (2000). A firm as a knowledge-creating entity: A new perspective on the theory of the firm. Industrial and Corporate Change, 9(1), $1-20$.

Okunoye, A., \& Bertaux, N. (2006). KAFRA: A context-aware framework of knowledge management in global diversity. International Journal of Knowledge Management, 2(2), 26-45.

Oliver, C. (1991). Strategic responses to institutional processes. Academy of Management Review, 16(1), 145-179.

Orlikowski, W. J. (1992). The duality of technology: Rethinking the concept of technology in organisations. Organisation Science, 3(3), 398-427.

Orlikowski, W. J. (1996). Improvising organizational transformation over time: A situated change perspective. Information Systems Research, 7(1), 63-92.

Orlikowski, W. J. (2000). Using technology and constituting structures: A practice lens for studying technology in organisations. Organisation Science, 11(4), 404-428.

Orlikowski, W. J., \& Barley, S. (2001). Technology and institutions. MIS Quarterly, 25(2), 145-165.

Orlikowski, W. J., \& Scott, S. V. (2008). The entangling of technology and work in organisations. Working Paper Series, Innovation Systems and Innovation Group London School of Economics, University of London.
Pettigrew, A. M., Woodman, R. W., \& Cameron, K. S. (2001). Studying organizationa change and development: Challenges for future research. Academy of Management Journal, 44(4), 697-713.

Porter, M. E. (1996, November-December). What is strategy? Harvard Business Review, 61-78, http://cfe.unc.edu/pdfs/what_is_strategy.pdf.

Powell, W. W., \& DiMaggio, P. J. (1991). The new institutionalism in organizationa analysis. Chicago, IL: University of Chicago Press.

Pozzebon, M. (2001). Demystifying the rhetorical closure of ERP packages. In Proceedings of the twenty-second international conference on information systems.

Purvis, R. L., Sambamurthy, V., \& Zmud, R. W. (2001). The assimilation of knowledge platforms in organizations: An empirical investigation. Organization Science, 12(2), 117-135

Remus, U. (2007). Critical success factors for implementing enterprise portals: A comparison with ERP implementations. Business Process Management Journal, 13(4), 538-552.

Rizzi, C., Ponte, D., \& Bonifacio, M. (2009). A new institutional reading of knowledge management technology adoption. Journal of Knowledge Management, 13(4), 75-85.

Robertson, M., Scarbrough, H., \& Swan, J. (2003). Knowledge creation in professional service firms: Institutional effects. Organization Studies, 24(6), 831-857.

Robertson, M. J., \& Swan, J. A. (2003). Control - What control? Culture and ambiguity within a knowledge intensive firm. Journal of Management Studies, 40, 831-858.

Robey, D., Ross J.W., \& Boudreau, M.-C. (2002). Learning to implement enterprise systems: An exploratory study of the dialectics of change. Journal of Managemen Information Systems, 19(1), 17-46.

SAIGlobal. (2007). AS 5037-2005: Knowledge management - A guide. Available at: http://www.saiglobal.com/shop/script/Details.asp?docn=AS0733769306AT Accessed 29.03.07

Schein, E. (1978). Career dynamics: Matching individual and organizational needs Reading, MA: Addison-Wesley.

Schultze, U., \& Boland, R. J. (2000). Knowledge management technology and the reproduction of knowledge work practices. Journal of Strategic Information Systems, 9, 193-212.

Schultze, U., \& Orlikowski, W. J. (2004). A practice perspective on technology mediated network relations: The use of Internet-based self-serve technologies. Information Systems Research, 15(1), 87-106.

Scott, W. R. (1987). The adolescence of institutional theory. Administrative Science Quarterly, 32(4), 493-511.

Scott, W. R. (1995). Institutions and organizations. Thousand Oaks, CA: Sage.

Sia, S. K., \& Soh, C. (2007). An assessment of package-organisation misalignment: Institutional and ontological structures. European Journal of Information Systems 16(5), 568-583.

Soh, C., Kien, S. S., \& Tay-Yap, J. (2000). Cultural fits and misfits: Is ERP a universal solution? Communications of the ACM, 43(4), 47-51.

Soh, C., \& Sia, S. K. (2004). An institutional perspective on sources of ERP package-organisation misalignments. Journal of Strategic Information Systems, 13, 375-397.

Soh, C., Sia, S. K., Wai, F. B., \& May, T. (2003). Misalignments in ERP implementation: A dialectic perspective. International Journal of Human Computer Interaction, 16(1), 81-100.

Spender, J. C. (1996). Making knowledge the basis of a dynamic theory of the firm. Strategic Management Journal, 17(Special Issues), 45L 62.

Spender, J. C. (1995). Organizations are activity systems, not merely systems of thought. Advances in Strategic Management, 12B, 23-47.

Spender, J. C. (2006). Knowledge management technology, and organization. In A Salazar, \& S. Sawyer (Eds.), Handbook of information technology in organizations and electronic markets (pp. 1-35). Toh Tuck Link, Singapore: World Scientific Press.

Teece, D. J., Pisano, G., \& Shuen, A. (1997). Dynamic capabilities and strategic management. Strategic Management Journal, 18(7), 509-533.

Teo, T. S. H., \& Men, B. (2008). Knowledge portals in Chinese consulting firms: A tasktechnology fit perspective. European Journal of Information Systems, 17, 557-574

Tiwana, A. (2000). The knowledge management toolkit. Upper Saddle River: PrenticeHall.

Vaast, E., \& Walsham, G. (2005). Representations and actions: The transformation of work practices with IT use. Information and Organization, 15, 65-89.

Wagner, E. L., \& Newell, S. (2004). Best for whom? The tension between 'best practice' ERP packages and diverse epistemic cultures in a university context. Journal of Strategic Information Systems, 13(4), 305-328.

Walsham, G. (2001). Making a world of difference: IT in a global context. Chichester: Wiley.

Walsham, G. (2002). Cross-cultural software production and use: A structurationa analysis. MIS Quarterly, 26(4), 359-382.

Walsham, G. (2008). ICTs and global working in a non-flat world. In M. Barrett, E. Davidson, C. Middleton, \& J. DeGross (Eds.), Information technology the service economy: Challenges possibilities for the 21st century (Vol. 267) IFIP international federation for information processing (pp. 13-25). Boston: Springer.

Weerakkody, V., Dwivedi, Y. K., \& Irani, Z. (2009). The diffusion and use of institutional theory: A cross-disciplinary longitudinal literature survey. Journal of Information Technology, 24, 354-368.

Yin, R. (1994). Case study research: Design and methods (2nd ed.). Thousand Oaks, CA: SAGE Publication.

Zakaria, N., Amelinckx, A., \& David, W. (2004). Working together apart? Building a knowledge-sharing culture for global virtual teams. Creativity and Innovation Management, 13, 15-29. 